\title{
Codeficiency of Lysosomal Mucolipins 3 and 1 in Cochlear Hair Cells Diminishes Outer Hair Cell Longevity and Accelerates Age-Related Hearing Loss
}

\author{
(i)Teerawat Wiwatpanit, ${ }^{1,2}$ Natalie N. Remis, ${ }^{1,2}$ Aisha Ahmad, ${ }^{3}$ Yingjie Zhou, ${ }^{3}$ John C. Clancy, ${ }^{2}$ Mary Ann Cheatham, \\ and ㄱaime García-Añoveros ${ }^{1,2,4,5}$ \\ ${ }^{1}$ Driskill Graduate Program in Life Sciences, Northwestern University, Chicago, Illinois 60611, 2Department of Anesthesiology, Northwestern University, \\ Feinberg School of Medicine, Chicago, Illinois 60611, ${ }^{3}$ Communication Sciences and Disorders Knowles Hearing Center, Northwestern University, \\ Evanston, Illinois 60208, ${ }^{4} \mathrm{Hugh}$ Knowles Center for Clinical and Basic Science in Hearing and Its Disorders, Northwestern University, Chicago, Illinois \\ 60611, and 5epartments of Neurology and Physiology, Northwestern University, Feinberg School of Medicine, Chicago, Illinois 60611
}

Acquired hearing loss is the predominant neurodegenerative condition associated with aging in humans. Although mutations on several genes are known to cause congenital deafness in newborns, few genes have been implicated in age-related hearing loss (ARHL), perhaps because its cause is likely polygenic. Here, we generated mice lacking lysosomal calcium channel mucolipins 3 and 1 and discovered that both male and female mice suffered a polygenic form of hearing loss. Whereas mucolipin 1 is ubiquitously expressed in all cells, mucolipin 3 is expressed in a small subset of cochlear cells, hair cells (HCs) and marginal cells of the stria vascularis, and very few other cell types. Mice lacking both mucolipins 3 and 1, but not either one alone, experienced hearing loss as early as at 1 month of age. The severity of hearing impairment progressed from high to low frequencies and increased with age. Early onset of ARHL in these mice was accompanied by outer $\mathrm{HC}(\mathrm{OHC})$ loss. Adult mice conditionally lacking mucolipins in HCs exhibited comparable auditory phenotypes, thereby revealing that the reason for $\mathrm{OHC}$ loss is mucolipin codeficiency in the $\mathrm{HCs}$ and not in the stria vascularis. Furthermore, we observed that $\mathrm{OHCs}$ lacking mucolipins contained abnormally enlarged lysosomes aggregated at the apical region of the cell, whereas other organelles appeared normal. We also demonstrated that these aberrant lysosomes in OHCs lost their membrane integrity through lysosomal membrane permeabilization, a known cause of cellular toxicity that explains why and how OHCs die, leading to premature ARHL.

Key words: ARHL; hearing; lysosome; mucolipin; presbycusis; TRPML

Significance Statement

Presbycusis, or age-related hearing loss (ARHL), is a common characteristic of aging in mammals. Although many genes have been identified to cause deafness from birth in both humans and mice, only a few are known to associate with progressive ARHL, the most prevalent form of deafness. We have found that mice lacking two lysosomal channels, mucolipins 3 and 1, suffer accelerated ARHL due to auditory outer hair cell degeneration, the most common cause of hearing loss and neurodegenerative condition in humans. Lysosomes lacking mucolipins undergo organelle membrane permeabilization and promote cytotoxicity with age, revealing a novel mechanism of outer hair cell degeneration and ARHL. These results underscore the importance of lysosomes in hair cell survival and the maintenance of hearing.

\section{Introduction}

In the cochlea, sounds are mechanotransduced by hair cells (HCs) of two types, inner HCs (IHCs) and outer HCs (OHCs).

Received Nov. 28, 2017; revised Jan. 16, 2018; accepted Feb. 2, 2018.

Author contributions: T.W. and J.G.-A. wrote the first draft of the paper; T.W., N.N.R., M.A.C., and J.G.-A. designed research; T.W., N.N.R., A.A., Y.Z., J.C.C., and M.A.C. performed research; T.W., A.A., Y.Z., J.C.C., M.A.C., and J.G.-A. analyzed data; T.W. and J.G.-A. wrote the paper.

This work was supported by National Institutes of Health Grants R01 HD086719 and R01 DC015903 to J.G.-A. and Grant DC000089 to M.A.C. The genetically engineered mice were generated with the assistance of the Transgenic and Targeted Mutagenesis Laboratory, supported in part by National Institutes of Health Grant CA60553 to the
While OHCs mechanically amplify sound-induced vibrations of the organ of Corti (Dallos and Fakler, 2002), IHCs signal synap-

Robert H. Lurie Comprehensive Cancer Center at Northwestern University. Imaging work was performed at the Northwestern University Center for Advanced Microscopy supported by National Cancer Institute Grant CCSG P30 CA060553 to the Robert H. Lurie Comprehensive Cancer Center.

The authors declare no competing financial interests.

Correspondence should be addressed to Dr. Jaime García-Añoveros, Northwestern University, 303 East Chicago Avenue, Ward10-070, Chicago, IL60611. E-mail: anoveros@northwestern.edu.

DOI:10.1523/JNEUROSCI.3368-17.2018

Copyright $\odot 2018$ the authors $\quad 0270-6474 / 18 / 383177-13 \$ 15.00 / 0$ 
tically to cochlear neurons, communicating auditory information to the brain (Dannhof and Bruns, 1993; Seal et al., 2008). In order for these cells to transduce sounds properly, the stria vascularis maintains a potassium-rich environment in the endolymphatic compartment of the cochlea, which registers a large positive potential (Wangemann, 2006). Damage to sensory, strial, and/or neuronal components can lead to hearing impairment. The most prevalent type of deafness is that acquired with age, termed presbycusis or age-related hearing loss (ARHL), and its most common cause is death of cochlear HCs, particularly of the more vulnerable OHCs (Ohlemiller, 2006; Liberman, 2017). Because mammalian HCs are not generated after an early developmental period, the deafness caused by their loss is irreversible. But for the same reason cochlear HCs must be remarkably resilient, they withstand constant high-energy demands and mechanical stimulations, and yet many survive for the lifetime of the organism, which in humans can amount for over a century. Hence, identification of genes involved in ARHL could lead to elucidating the molecular mechanisms responsible for HC longevity. Despite its prevalence, only a few genes are known to associate with progressive ARHL (Ohlemiller, 2006), probably because the loss is polygenic. One approach to study polygenic ARHL has been to map the multiple loci contributing to hearing loss observed in certain strains of mice (Noben-Trauth et al., 2003; Noguchi et al., 2006; Ohlemiller et al., 2008; Keller et al., 2011). In an alternative approach, we generated double knock-out mice lacking two genes suspected to function in degeneration of cochlear cells but that, when mutated alone, did not cause deafness.

Mucolipins constitute a group of Transient Receptor Potential (TRP) cation channels present in the membranes of lysosomes and late endosomes. In mammals, there are three mucolipins (also known as TRPML1, 2, and 3), encoded by the genes Mcoln 1, 2, and 3 (hereby referred to as Trpml1, 2, and 3) (Montell, 2005; Zeevi et al., 2007; García-Añoveros and Wiwatpanit, 2014). Loss-offunction mutations in the human Trpml1 gene cause mucolipidosis Type IV (MLIV), a lipid storage disease resulting in lysosomal overload and cellular degeneration (Schiffmann et al., 1993; Slaugenhaupt, 2002). Trpml1 ${ }^{-/-}$mice appear normal for the first 6-8 months of age, at which time they develop MLIVlike symptoms (motor incoordination, retinal degeneration, and loss of body fat) and die within 2 weeks (Venugopal et al., 2007; Micsenyi et al., 2009). A dominant mutation in the Trpml3 gene causes deafness and vestibular impairment characterized by $\mathrm{HC}$ loss, anatomical malformation of the stria vascularis, and reduced endocochlear potential in the Varitint-Waddler ( $\mathrm{Va})$ mouse (Cable and Steel, 1998; Di Palma et al., 2002). This gainof-function mutation resulted in channels with an increased open probability that sustained a constitutive cationic current lethal to cells (Grimm et al., 2007; Kim et al., 2007; Xu et al., 2007; Nagata et al., 2008), which explains the HC death and deafness of the $\mathrm{Va}$ mice (Nagata et al., 2008; Castiglioni et al., 2011). However, because the Va mutation results in constitutively active mucolipin 3 channels, it does not reveal the contribution this channel may make to HCs and hearing, which requires a null mutation lacking functional mucolipin 3.

Trpml3 $3^{-/-}$mice display no hearing impairment or any other phenotype examined (Jörs et al., 2010; Remis et al., 2014), prompting the suspicion that there are one or more genes with redundant functions. Two obvious candidates are the remaining mucolipins, Trpml1 and Trpml2. Mucolipin 2 is expressed in immune cells and not in most mucolipin 3-expressing cells, including HCs (Montell, 2005; Zeevi et al., 2007; García-Añoveros and Wiwatpanit, 2014). However, mucolipin 1 is ubiquitous
(Bach, 2001; LaPlante et al., 2002; Bach et al., 2005) and thus could act redundantly with mucolipin 3 , as shown in neonatal enterocytes, which express high levels of both mucolipins 3 and 1 and have specialized giant lysosomes. These cells were severely vacuolated in mice lacking both mucolipins 3 and 1, but not either one alone. This pathology involved an enlargement of the specialized lysosomes characteristic of neonatal enterocytes (Remis et al., 2014). We reasoned that mucolipins 3 and 1 may also act redundantly in the inner ear.

Here, we generated mice lacking mucolipin 3 and mucolipin 1 in HCs. Mice lacking lysosomal mucolipins 3 and 1 in HCs displayed hearing loss progressing from high to low frequencies and with age. Absence of both mucolipins in OHCs caused enlargement and permeabilization of lysosomes, a known source of cellular toxicity, and $\mathrm{OHC}$ degeneration. These results represent a novel polygenic form of ARHL that involves two lysosomal channels and a lysosomal mechanism in the degeneration of OHCs with age.

\section{Materials and Methods}

Ethics. All animal care and procedures were in accordance with the Guide for the care and use of laboratory animals published by the National Institutes of Health and were approved by Northwestern University's Institutional Animal Care and Use Committee (Animal Study Protocols: IS00000593, IS00001281, and IS00003625).

Animals. Wild-type (WT) and Trpml1 ${ }^{-1}$ (ML1KO) mice in this study were littermates generated by mating Trpml1 $1^{+/-} \times \operatorname{Trpml1}^{+/-}$, and had a genetic background of $\sim 75 \%$ C57BL/6 and $\sim 25 \% 129 S 6$ (Venugopal et al., 2007). Trpml3 ${ }^{-/-}$(ML3KO) and Trpml3 ${ }^{-/-} ; \operatorname{Trpml1}^{-/-}$(double knock-out $[\mathrm{DKO}])$ were littermates generated by mating $\operatorname{Trpml} 3^{-1-}$; $\operatorname{Trpml1}^{+/-} \times \operatorname{Trpml3}^{-/-} ; \operatorname{Trpml1}^{+/-}$, and had a genetic background of $\sim 75 \%$ C57BL/6, 12.5\% Sv129/Ola, and 12.5\% 129 S6 (Castiglioni et al., 2011; Remis et al., 2014). Finally, mice conditionally lacking mucolipins in $\mathrm{HCs}$ only $\left(\mathrm{Gfil}^{\mathrm{Cre} /+}\right.$; $\operatorname{Trpml}^{\mathrm{F} / \mathrm{F}} ; \mathrm{Trpm} 1^{-/-}$, conditional DKO $[\mathrm{cDKO}])$ and their littermate controls $\left(\mathrm{Gfi}^{+/+} ; \operatorname{Trpml3}^{\mathrm{F} / F} ; \operatorname{Trpml1}^{-/-}\right.$, $\mathrm{Gfi}^{+/+} ; \operatorname{Trpml3}^{F / F} ; \operatorname{Trpml1}^{+/+}, \mathrm{Gfi}^{+/+} ; \operatorname{Trpml3}{ }^{F / F} ; \operatorname{Trpml1}^{+/-}, \mathrm{Gfi} \mathrm{Cre} /+^{-}$ $\operatorname{Trpml3}^{\mathrm{F} / \mathrm{F}} ; \mathrm{Trpml1}^{+/+}, \mathrm{Gfi}^{\mathrm{Cre} /+} ; \operatorname{Trpml}^{\mathrm{F} /+} ; \mathrm{Trpml1}^{+/+}$and $\mathrm{Gfi}^{\mathrm{Cre} /+}$; $\operatorname{Trpml}^{\mathrm{F} /+} ; \operatorname{Trpml1}^{+/-}$) incorporated $\mathrm{Gfil}^{\mathrm{Cre} /+}$ mice with a mixed background of C57BL/6J and 129S6 (Yang et al., 2010), and had an estimated background of $\sim 59 \%$ C57BL/6, 19\% Sv129/Ola, and 22\% 129S6. Hence, all animals used in this study had a similar genetic background of $59 \%-75 \%$ C57BL/6 and 41\%-25\% 129 strains. Importantly, regardless of the slight differences in genetic background, ML1KO mice (littermates of WT) and ML3KO (littermates of DKO) did not differ from WT mice in all aspects examined. Furthermore, $\mathrm{CDKO}$ and $\mathrm{DKO}$, although not littermates, had comparable auditory brainstem response $(\mathrm{ABR})$ and distortion product otoacoustic emission (DPOAE) thresholds and virtually identical patterns of $\mathrm{HC}$ loss. Hence, the slight differences in genetic background did not result in any auditory phenotype, nor did they alter the hearing and HC loss phenotype segregating with mucolipin codeficiency.

Hearing tests. During testing, mice of both sexes aged $\sim$ P30 and between P60 and P120 were anesthetized with ketamine/xylazine $(100 \mathrm{mg} /$ $\mathrm{kg} / 10 \mathrm{mg} / \mathrm{kg}$, i.p.), and their body temperature was maintained using a heating blanket. Hearing tests were performed on the left ear. DPOAEs were acquired using a custom probe and an in the ear calibration. To determine DPOAE threshold, growth or input-output functions were collected for $\mathrm{f} 2=12 \mathrm{kHz}$ and for $\mathrm{f} 2=27 \mathrm{kHz}$ (where $\mathrm{f} 2=1.2 \times \mathrm{f} 1$ ) with the level of $\mathrm{f} 1$ being $10 \mathrm{~dB}$ higher than $\mathrm{f} 2$. These functions were plotted off line, and the sound pressure level of $\mathrm{fl}$ that produced a cubic difference tone at $2 \mathrm{f} 1-\mathrm{f} 2$ of $0 \mathrm{~dB}$ was defined as threshold. ABRs were also acquired to assay auditory nerve activity as well as that in the lower brainstem. For these recordings, subcutaneous needle electrodes were inserted at the vertex and at the mastoid with a reference electrode in the neck region on the opposite side. ABR thresholds were obtained using short tone bursts of decreasing level ( step size $=5 \mathrm{~dB}$ ). Threshold was defined as the level 
where all ABR waves disappeared into the noise floor. The details of these procedures appear in a previous publication (Cheatham et al., 2014).

Tissue collection and processing. For neonatal tissues (younger than P14), the animals were killed by decapitation and inner ears dissected in ice-cold PBS. For adult tissues (older than P21), the inner ears were dissected following cardiac perfusion with $2 \%$ or $4 \%$ PFA after death. Tissues collected from both male and female mice were then postfixed in $2 \%$ or $4 \%$ PFA for $2 \mathrm{~h}$ at room temperature. Adult ears were decalcified either in RDO (Electron Microscopy Sciences) at room temperature for $10 \mathrm{~min}$ or in $10 \%(\mathrm{w} / \mathrm{v})$ EDTA, pH 7.3-7.4, at $4^{\circ} \mathrm{C}$ for at least $24 \mathrm{~h}$. To prepare frozen sections, the ears were processed and sectioned at $12 \mu \mathrm{m}$ as described previously (Castiglioni et al., 2011). For whole-mount preparations, the organ of Corti was dissected from the cochlea into one apical, two middle, and one basal segment using a whole-mount surface preparation method described previously (Montgomery and Cox, 2016).

Immunohistochemistry. Frozen sections were processed as previously described (Castiglioni et al., 2011). The antibodies used for frozen tissue preparation were as follows: TRPML3-CT (1:5000, a gift from Dr. Markus Delling, University of California, San Francisco), lysosomalassociated membrane protein 1 (LAMP1, 1:50, 1D4B-s, Developmental Studies Hybridoma Bank), and KCNQ1 (1:100, sc-20816, Santa Cruz Biotechnology). For TRPML3-CT immunostaining, the sections were subjected to antigen retrieval by incubating in $10 \mathrm{~mm}$ sodium citrate, $\mathrm{pH}$ 6, with $0.25 \%$ Triton $\mathrm{X}-100$ for $20 \mathrm{~min}$ at $92^{\circ} \mathrm{C}$ and cooling for $30 \mathrm{~min}$ at room temperature before blocking, and TRPML3-CT immunoreactivity was detected using a SuperBoost tyramide signal amplification kit (B40922, Thermo Fisher Scientific). Whole-mount organ of Corti sections were processed for immunohistochemistry as described previously (Delmaghani et al., 2015). The antibodies used for whole-mount preparation were LAMP1 (1:50), LC3 (1:50, ab58610, Abcam), PMP70 (1:100, ab3421, Abcam), COXIV (1:100, ab16056, Abcam), and Galectin 3 (1:50, ab58802, Abcam). Nuclei were counterstained with DAPI (1:1000, Thermo Fisher Scientific) and stereocilia with the filamentous actin probe phalloidin (1:100, Thermo Fisher Scientific).

Image acquisition. For immunohistochemistry on frozen sections, we acquired images on either a Leica SP5 confocal or Nikon E600 pan fluorescence microscope equipped with a Nikon DS-Ri2 camera. For wholemount preparation, we acquired images on either a Nikon Al confocal, Nikon A1R + Confocal or Nikon N-structured illumination microscopy structured illumination super-resolution microscope imaging system using a $100 \times$ objective. Three-dimensional renderings of confocal images were generated using NIS Elements AR4.60.00 (Nikon) and Imaris X64 8.4.1 (BitPlane) software. Organelle number and volume measurements were performed using built-in analysis functions on Imaris. When comparing controls and mutant immunoreactivities, we captured images with identical settings. After acquisition, we identically processed image pairs of control and knock-out samples. This included adjustment for brightness and contrast.

Cytocochleogram construction. We used the right cochlea, not previously subjected to hearing tests, for cytocochleogram construction. For each cochlea, all 4 segments from a single whole-mount surface preparation were counterstained for stereocilia. Images were captured at $20 \times$, stitched and reconstructed using either MicroSuite FIVE (Olympus Soft Imaging Solutions) or FIJI (ImageJ). After calculating cochlear length and dividing the cochlea into $7 \%$ segments, cytocochleograms were constructed by plotting the average percentage HC loss, determined by the absence of stereocilia staining in each 7\% segment along the basilar membrane. Cochlear positions corresponding to 12 and $27 \mathrm{kHz}$ were calculated using a mouse frequency-place map (Müller et al., 2005).

Experimental design and statistical analysis. For statistical analysis, data were collected from both male and female animals. All statistical tests were performed using Prism software (GraphPad). For consistency, all whole-mount surface preparation measurements were performed on cochlear middle segments, whereas frozen section measurements were on cochlear middle turns of midmodiolar sections. Data are mean \pm SEM shown in all plots. Datasets were analyzed for significance using a oneway ANOVA followed by either Tukey's or Dunnett's post hoc tests or unpaired $t$ test based on the $n=$ number of animals, and only one ear per animal was used. The statistical comparison of hearing thresholds in $\sim$ P30 DKO versus adult WT, ML1KO, and ML3KO (see Fig. $1 A-D$ ), as well as the comparisons of $\mathrm{HC}$ loss in controls (WT, ML1KO, and ML3KO) versus both complete and conditional double knock-out mice (DKO and cDKO) (see Fig. $4 F$ ), were unpaired $t$ tests. For all anatomical examinations and immunostainings, we used cochlea from the ears that were not subjected to hearing tests. The number of cells used to collect individual data are shown on the plots. A 95\% CI was used to determine significance $(p<0.05)$. All sample size and $p$ values are reported in the figures or the figure legends.

\section{Results}

Mice lacking mucolipins 3 and 1 experience accelerated ARHL To examine the role of lysosomal mucolipins in auditory function, we tested the hearing of mice lacking mucolipin 1 (ML1KO), lacking mucolipin 3 (ML3KO), and lacking both mucolipins 3 and 1 (DKO), by determining their DPOAE and ABR thresholds at high $(27 \mathrm{kHz})$ and low $(12 \mathrm{kHz})$ frequencies. ABRs measure auditoryevoked neural output from the cochlea to the brainstem (Willott, 2006), whereas DPOAEs reflect OHC function. The latter are measured from the ear canal by presenting a two-tone stimulus (Martin et al., 2006). Adult mice ( P60-P120) lacking either mucolipin 1 or 3 alone (ML1KO or ML3KO) had comparable $\mathrm{ABR}$ and DPOAE thresholds to WT animals at both 27 and 12 $\mathrm{kHz}$ (Fig. $1 A-D$ ). However, adult DKO mice had significantly higher ABR and DPOAE thresholds than controls (WT, ML1KO, and ML3KO), indicating hearing loss (Fig. $1 A, B$ ). The raised $\mathrm{ABR}$ and DPOAE thresholds in DKO mice are similar, a characteristic of OHC dysfunction. The ABR threshold shift for DKO mice is greater at high $(27 \mathrm{kHz})$ frequency $(61.61 \pm 4.57 \mathrm{~dB})$ than at low $(12 \mathrm{kHz})$ frequency $(21.57 \pm 3.66 \mathrm{~dB}$; Fig. $1 \mathrm{~A}, C)$. The DPOAE threshold shift is also larger at $27 \mathrm{kHz}$ (at least $43.47 \pm$ $1.40 \mathrm{~dB}$; this is an underestimate because we could not detect thresholds $>90 \mathrm{~dB})$ than at $12 \mathrm{kHz}(28.28 \pm 2.96 \mathrm{~dB})$ (Fig. $1 B, D)$. These data suggest that DKO mice experience hearing loss, which progresses from high to low frequencies, a characteristic of ARHL.

Juvenile (P30) DKO mice already exhibit some hearing loss, which, as in the adult, is more pronounced at 27 than at $12 \mathrm{kHz}$ (Fig. 1A-D). ABR threshold shifts of juvenile DKO mice (26.36 \pm $3.99 \mathrm{~dB}$ at $27 \mathrm{kHz}$ and $9.97 \pm 3.82 \mathrm{~dB}$ at $12 \mathrm{kHz}$ ) are smaller than the threshold shifts of adult DKO mice $(61.61 \pm 4.57 \mathrm{~dB}$ at 27 $\mathrm{kHz}$ and $21.57 \pm 3.66 \mathrm{~dB}$ at $12 \mathrm{kHz}$ ) (Fig. $1 \mathrm{~A}, \mathrm{C}$ ). Similarly, juvenile DKO mice also exhibit DPOAE threshold shifts (31.15 \pm $2.64 \mathrm{~dB}$ at $27 \mathrm{kHz}$ and $10.23 \pm 3.39 \mathrm{~dB}$ at $12 \mathrm{kHz}$ ), but the loss of sensitivity is again less than in older adult DKO animals (Fig. $1 B, D)$. Together, our data indicate that mice lacking both mucolipins 3 and 1 suffer an early onset form of ARHL.

\section{Mucolipin 3 and 1 coabsence in HCs causes ARHL}

In the cochlea, mucolipin 3 is expressed in both auditory HCs and stria vascularis (Castiglioni et al., 2011) (Fig. 2), whereas mucolipin 1 is ubiquitous (Bach, 2001; LaPlante et al., 2002; Bach et al., 2005). In neonatal cochleae (P11), mucolipin 3 is expressed in IHCs, OHCs, and stria vascularis in a cytoplasmic punctate pattern, consistent with its previously reported lysosomal localization in these cells (Castiglioni et al., 2011). Mucolipin $3 \mathrm{immu-}$ noreactivity is primarily located apically in OHCs but dispersed throughout the IHC cytoplasm (Fig. 2A,E). Our results only disagree with this prior report in one aspect: while it was believed that mucolipin 3 disappeared from mature OHCs, we now find that in the mature cochlea ( $\sim$ P120), OHCs maintain mucolipin 3 immunoreactivity, albeit at a lower level than IHCs (Fig. 2A). In stria vascularis, mucolipin 3 immunoreactivity appears dispersed 
A ABR $27 \mathrm{kHz}$

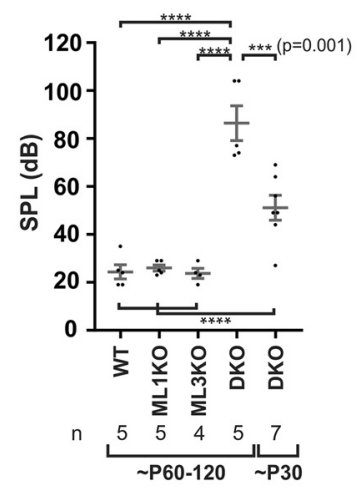

$E_{\text {ABR } 27 \mathrm{kHz}}$

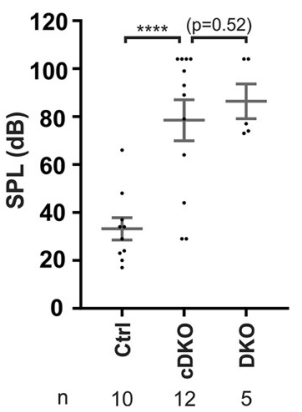

B DPOAE $27 \mathrm{kHz}$

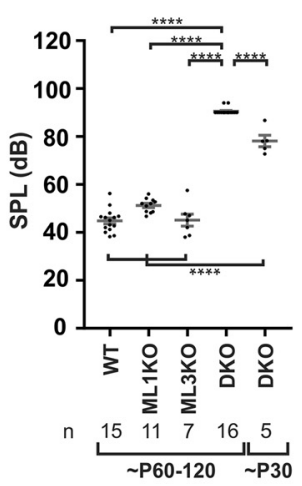

F DPOAE $27 \mathrm{kHz}$

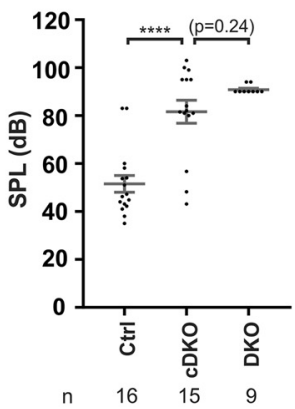

C ABR $12 \mathrm{kHz}$

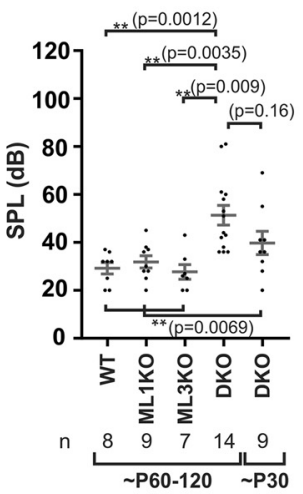

G ABR 12kHz

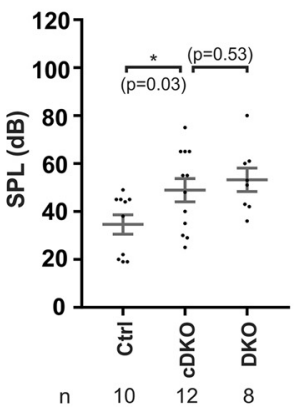

DPOAE 12kHz

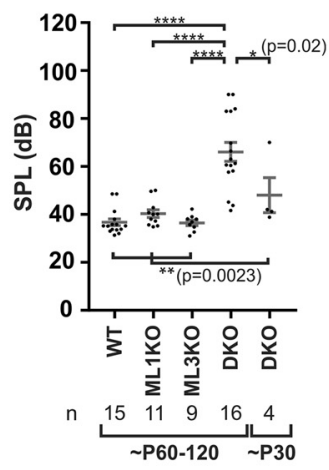

H DPOAE 12kHz

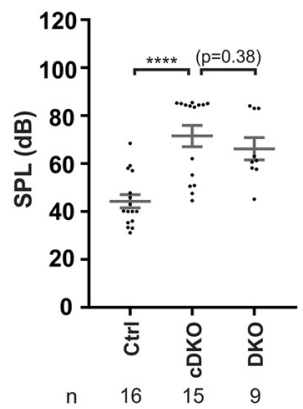

Figure 1. Coabsence of mucolipins 3 and 1 in $\mathrm{HCS}$, but not either alone, causes age-related hearing loss progressing from high to low frequencies. $\boldsymbol{A}-\boldsymbol{H}$, Hearing thresholds at 27 and $12 \mathrm{kHz}$ determined using $A B R s(\boldsymbol{A}, \boldsymbol{C}, \boldsymbol{E}, \boldsymbol{G})$ and DPOAEs $(\boldsymbol{B}, \boldsymbol{D}, \boldsymbol{F}, \boldsymbol{H})$ in adult ( $\sim$ P60 -P120) and juvenile ( P30) mice. $\boldsymbol{A}, \boldsymbol{B}$, Adult mice lacking both mucolipins 3 and 1 (DK0), but not either alone (ML1K0 or ML3KO), have raised ABR $(A)$ and DPOAE $(B)$ thresholds at $27 \mathrm{kHz}$ compared with WT mice. Juvenile DKO mice $(\sim \mathrm{P30})$ exhibit somewhat smaller threshold shifts at $27 \mathrm{kHz}$ for both ABR and DPOAE. $\boldsymbol{C}, \boldsymbol{D}$, Adult DKO mice have a mild hearing loss at $12 \mathrm{kHz}$ indicated by both ABR $(\boldsymbol{C})$ and DPOAE (D) threshold shifts. At $12 \mathrm{kHz}$, juvenile DKO mice have intermediate ABR and DPOAE threshold shifts. $\boldsymbol{E}-\boldsymbol{H}$, Hearing tests from mice in which mucolipins 3 and 1 are conditionally absent in $\mathrm{HCS}$ only (CDKO) indicate that adult $\mathrm{D} D \mathrm{~K} 0$ mice ( P120) have raised hearing thresholds at both $27(\boldsymbol{E}, \boldsymbol{F})$ and $12(\boldsymbol{G}, \boldsymbol{H}) \mathrm{kHz}$. Age-matched (P120) data from adult DKO mice from $(\boldsymbol{A}-\boldsymbol{D})$ were selected and replotted $(\boldsymbol{E}-\boldsymbol{H})$ to statistically compare the ABR $(\boldsymbol{E}, \boldsymbol{G})$ and DPOAE $(\boldsymbol{F}, \boldsymbol{H})$ thresholds between mice lacking mucolipins in all cells versus mice lacking mucolipins in $\mathrm{HCs}$ only. ${ }^{*} p<0.05 ;{ }^{* *} p<0.01 ;{ }^{* * *} p<0.001$; ${ }^{* * *} p<0.0001$.

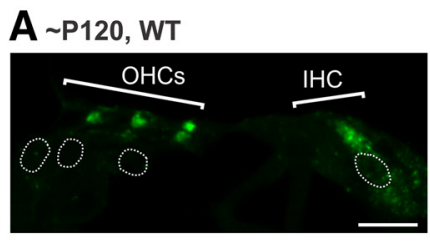

C P120, ML3KO
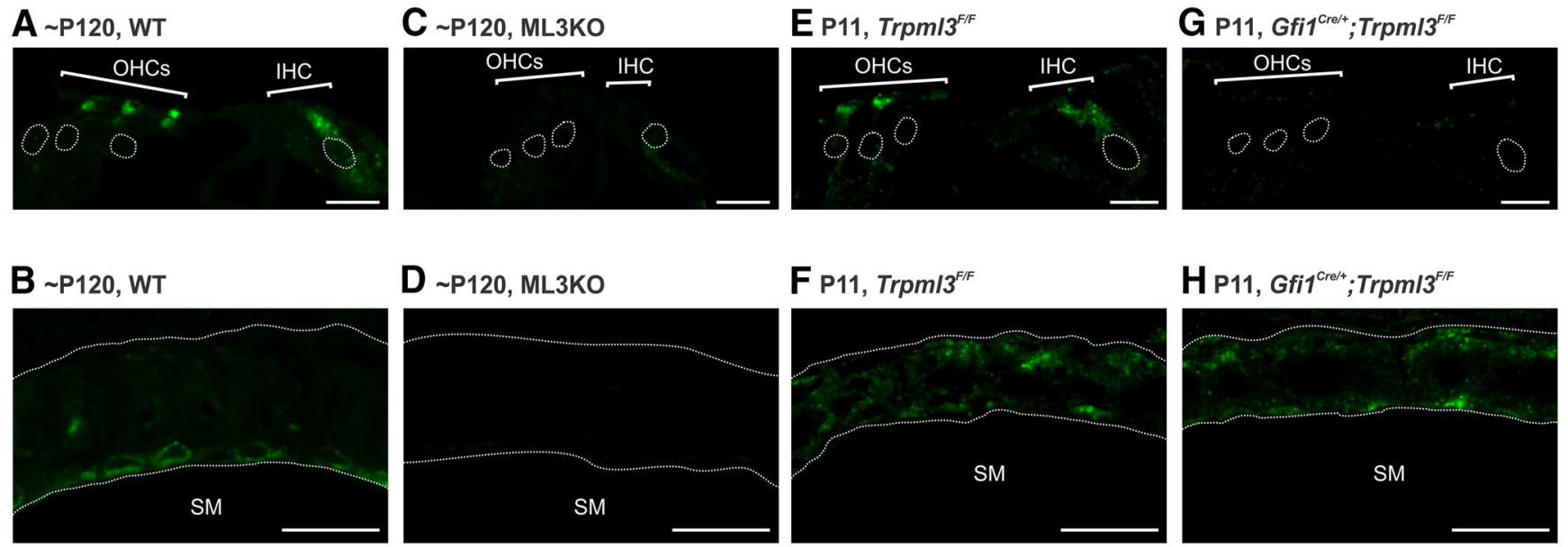

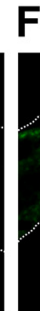

F P11, Trpm/3 ${ }^{F F}$

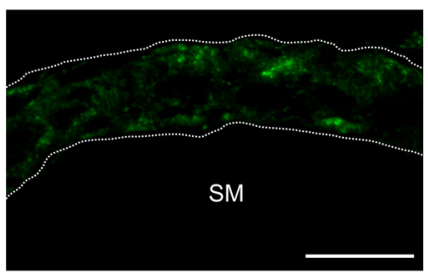

H P11, Gfi ${ }^{\text {Croot }} ;$ Trpm $^{\text {Fif }}$

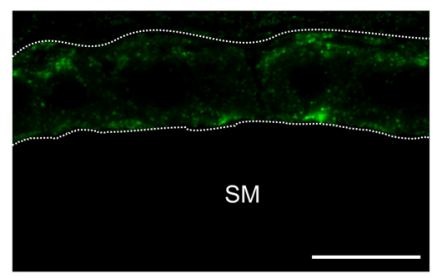

Figure 2. Mucolipin 3 is localized to HCs and the stria vascularis in both adult and neonatal cochleae. Immunohistochemistry of the mucolipin 3 carboxyl terminus (TRPML3-CT) on adult ( $\sim P 120)$ $(\boldsymbol{A}-\boldsymbol{D})$ and neonatal (P11) $(\boldsymbol{E}-\boldsymbol{H})$ cochleae. $\boldsymbol{A}$, TRPML3-CT labels vesicles in both IHCs and OHCs as well as cells of stria vascularis $(\boldsymbol{B})$ in WT cochlea. $\boldsymbol{C}, \boldsymbol{D}$, In ML3K0 tissues, there is no TRPML3-CT immunoreactivity detected above the background signals in either $\mathrm{HCS}(\boldsymbol{C})$ or stria vascularis $(\boldsymbol{D}) . \boldsymbol{E}, \boldsymbol{F}$, Neonatal $T r p m /{ }^{F / F} \mathrm{HCs}$ express mucolipin 3 in a similar pattern as adult $\mathrm{HCs}$; however, the levels of TRPML3-CT immunoreactivity in P11 OHCs and IHCs are comparable (E). Mucolipin 3 appears more dispersed in the P11 stria vascularis $(\boldsymbol{F})$. $\boldsymbol{G}, \boldsymbol{H}$, There is no TRPML3-CT immunoreactivity detected in $\mathrm{Gfi}^{\mathrm{Cre} /+} ; \operatorname{Trpm} / \mathrm{F}^{\mathrm{F} / \boldsymbol{F}} \mathrm{HCS}(\boldsymbol{G})$, although its signal is detected in the stria vascularis $(\boldsymbol{H})$. Scale bars: $\boldsymbol{A}, \boldsymbol{C}, \boldsymbol{E}, \boldsymbol{G}, 10 \mu \mathrm{m} ; \boldsymbol{B}, \boldsymbol{D}, \boldsymbol{F}, \boldsymbol{H}, 20 \mu \mathrm{m}$. For clarity, HC nuclei and strial boarder were outlined in top panels. SM, Scala media. 
A Stria Vascularis: KCNQ1 + DAPI
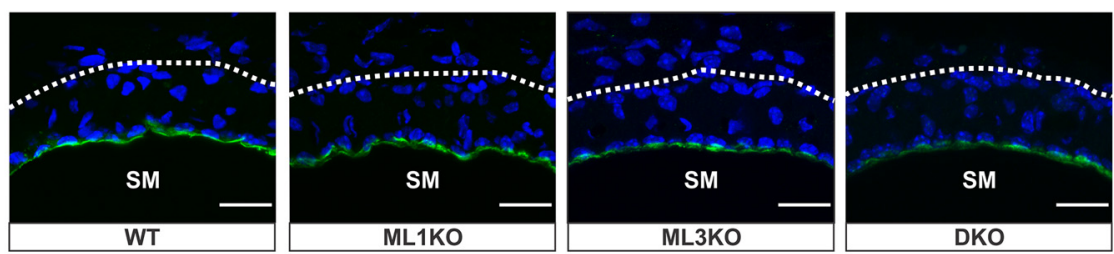

B

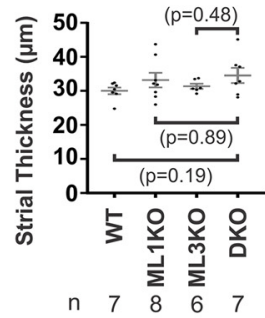

C oHC: Actin
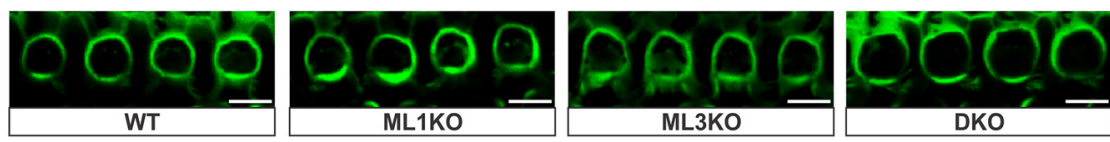

D IHC: Actin
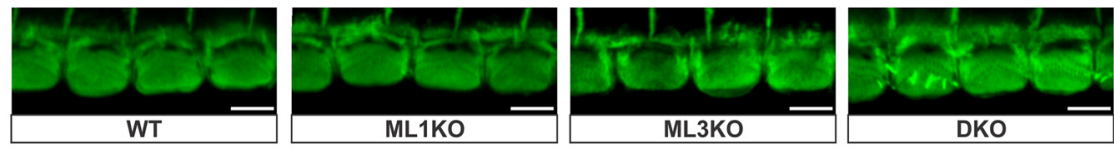

E

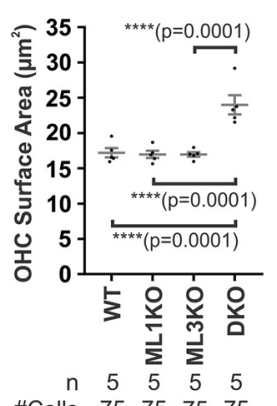

$\mathbf{F}$

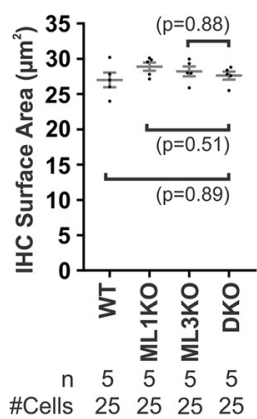

Figure 3. There is an anatomical defect in $\mathrm{OHCs}$ but not in the stria vascularis from cochleae lacking both mucolipin 3 and 1 .A, Immunoreactivity of potassium channel KCNQ1 in the stria vascularis shows that there is no mislocalization of this channel in DKO cochlea compared with WT, ML1KO, and ML3KO animals. SM, Scala media. $B$, Quantification of strial thickness indicates that there is no strial degeneration in $\mathrm{DKO}$ cochlea. $\boldsymbol{C}, \boldsymbol{D}$, Actin labeling reveals that $\mathrm{OHCS}(\boldsymbol{C}$, but not IHCS $(\boldsymbol{D})$, from DKO cochlea are larger than those of control cochleae. $\boldsymbol{E}, \boldsymbol{F}$, Quantification of $H C$ apical surface area, measured just under the cuticular plate of HCs from middle turn, confirms that DKO OHCs are larger than the controls. Samples were from 4- to 4.5-month-old animals. Scale bars: $A$, $20 \mu \mathrm{m}$; $C, D, 5 \mu \mathrm{m} .{ }^{* * * *} p \leq 0.0001$

at P11 but surrounds the nuclei of strial marginal cells by P120 (Fig. 2 B, F), as previously reported (Castiglioni et al., 2011). As a negative control and as evidence that the immunoreactivity was specific for TRPML3, immunohistochemistry in ML3KO tissues gave no signal above background in either HCs or stria vascularis (Fig. 2C,D). The restricted expression of mucolipin 3 in HCs and strial cells suggests that mucolipins could contribute to auditory functions of both HCs and stria vascularis.

Because defects in either HCs (Ohlemiller, 2006; Potter et al., 2016) or in stria vascularis can cause progressive loss of HCs and hearing (Gamp et al., 2003; Knipper et al., 2006; Ohlemiller et al., 2008), accelerated ARHL in DKO mice could be due to the coabsence of both mucolipins 3 and 1 in HCs and/or stria vascularis. To determine which cells require mucolipins 3 and 1 to maintain hearing, we used a floxed allele of Trpml3 (Remis et al., 2014), a complete KO of Trpml1 (Venugopal et al., 2007), and the HCspecific $\mathrm{Gfil}^{\mathrm{Cre}}$ line (Yang et al., 2010) to generate mice conditionally lacking both mucolipins 3 and 1 in HCs but not in strial cells (cDKO). In the cochlea of these mice, $G f_{i}^{\text {Cre }}$ ablates Trpml3 only in auditory HCs (Fig. 2E-H), whereas all cells lack mucolipin 1. Because animals lacking either mucolipin 1 or 3 alone do not experience hearing defects (Fig. $1 A-D$ ), we grouped together littermate controls for statistical analysis.

We found that adult $(\sim \mathrm{P} 120) \mathrm{cDKO}$ mice experienced hearing loss like DKO mice with comparable auditory threshold shifts and frequency dependence (Fig. 1). Specifically, ABR threshold shifts among adult $\mathrm{CDKO}$ were $45.30 \pm 10.31 \mathrm{~dB}$ at $27 \mathrm{kHz}$ and $14.32 \pm 6.51 \mathrm{~dB}$ at $12 \mathrm{kHz}$ (Fig. $1 E, G$ ). DPOAE threshold shifts for adult cDKO were $30.12 \pm 5.91 \mathrm{~dB}$ at $27 \mathrm{kHz}$ and $27.23 \pm 5.12$ $\mathrm{dB}$ at $12 \mathrm{kHz}$ (Fig. $1 F, H$ ). ABR and DPOAE threshold shifts were again more severe at high $(27 \mathrm{kHz}$, Fig. $1 E, F)$ than low $(12 \mathrm{kHz}$, Fig. $1 G, H)$ frequencies, the same pattern observed in adult DKO mice (Fig. $1 A-D$ ). Finally, ABR and DPOAE thresholds for $\sim$ P120 cDKO mice did not differ from those observed in $\sim$ P120 DKO mice (Fig. $1 E-H$ ). Hence, we concluded that coabsence of mucolipins 3 and 1 in HCs was the cause of the early-onset ARHL observed in our mouse models.

Lysosomal defects in stria vascularis can lead to progressive hearing loss. In particular, in mice mutant for lysosomal LIMP2, the potassium channel KCNQ1 is not localized to the apical membrane of strial marginal cells, and this leads to progressive hearing loss and HC degeneration (Gamp et al., 2003; Knipper et al., 2006). Hence, we examined the stria vascularis of mucolipincodeficient adult (4- to 4.5-month-old) mice. The stria vascularis was of normal thickness, and KCNQ1 was properly localized in DKO mice (Fig. $3 A, B$ ). The lack of an anatomical phenotype is consistent with the genetic evidence that mucolipins are required in HCs, but not in strial cells, to prevent early-onset ARHL.

On the other hand, we observed a small but consistent increase in OHC ( $\sim 1.4$-fold), but not IHC size, in DKO cochleae, determined by the surface area of HCs just under the cuticular plate (Fig. 3C-F). This could be an early sign of OHC dysfunction leading to hearing loss in mice lacking mucolipins 3 and 1 in HCs as cells in the process of dying are often swollen (Trump et al., 1997). These results further suggest that the lack of mucolipins 3 and 1 in HCs, especially OHCs, is likely the primary cause of early-onset ARHL in these mice.

\section{Mucolipin 3 and 1 coabsence in HCs causes OHC degeneration}

The most common cause of deafness and hearing loss is degeneration of OHCs. Hence, we examined the cochleae of adult $(\sim$ P120) mice subjected to hearing testing. At the cochlear positions associated with 27 and $12 \mathrm{kHz}$ (Müller et al., 2005), there is no IHC loss regardless of genotype (Fig. $4 A$ ). However, there is a high degree of OHC loss in DKO and cDKO cochleae, especially at the basal $27 \mathrm{kHz}$ place, but not in WT, ML1KO, and ML3KO controls (Fig. 4A-E). The level of $\mathrm{OHC}$ loss at the $\sim 27 \mathrm{kHz}$ 


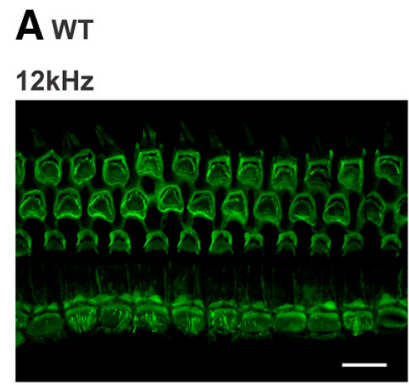

$27 \mathrm{kHz}$

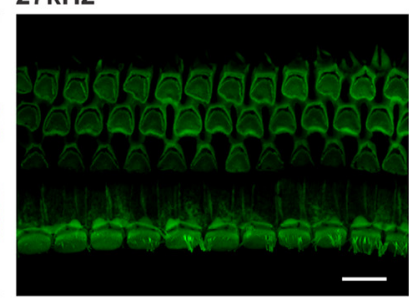

$\mathrm{C}_{\text {MLзKо }}$

$12 \mathrm{kHz}$

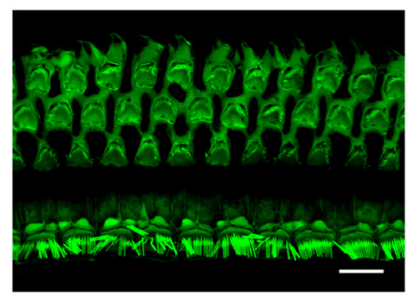

$\mathbf{E}_{\mathrm{CDKO}}$

$12 \mathrm{kHz}$
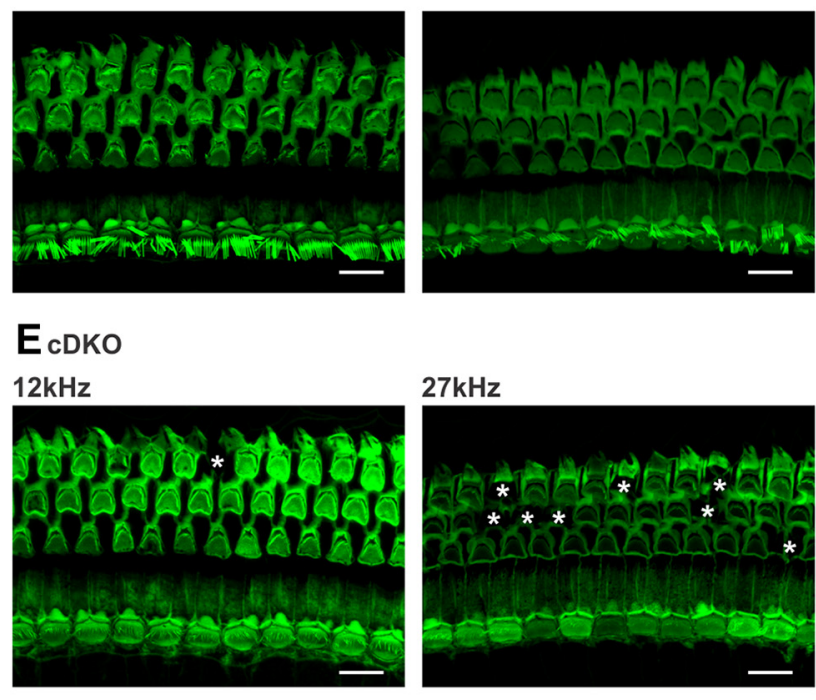

$27 \mathrm{kHz}$
B ML1KO

$12 \mathrm{kHz}$

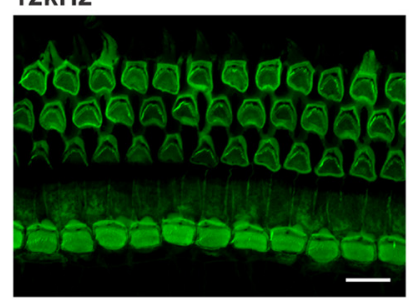

D DKо

$12 \mathrm{kHz}$

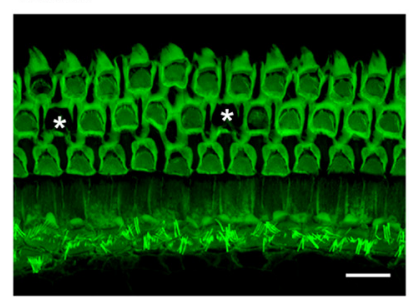

$27 \mathrm{kHz}$

F
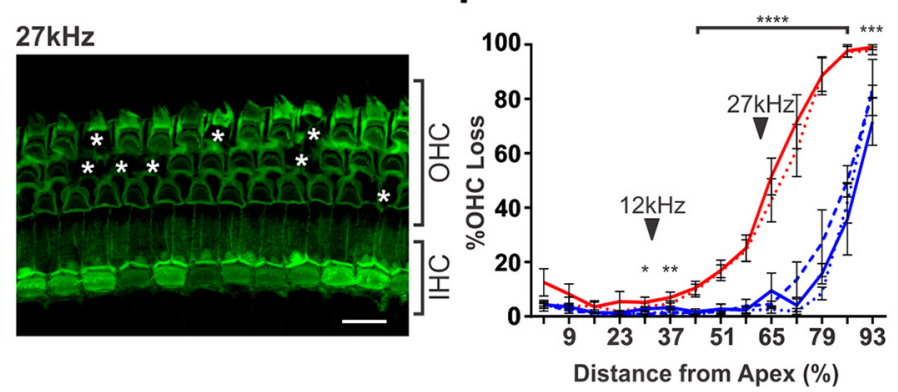

$27 \mathrm{kHz}$
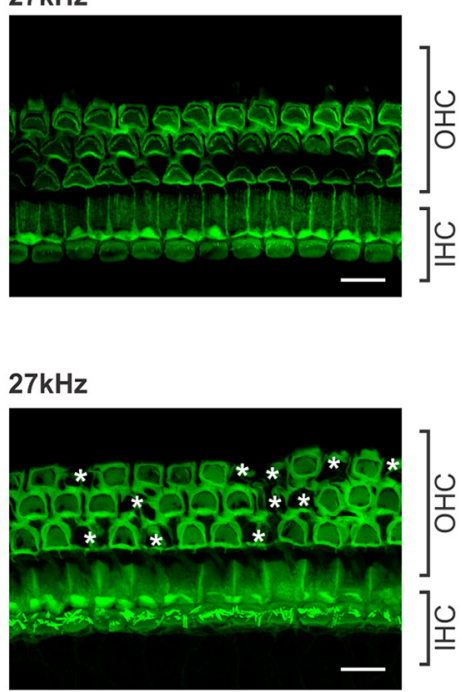

Figure 4. Age-related hearing loss in animals lacking both mucolipin 3 and 1 is accompanied by $0 H C$ death. $A-E$, Actin labeling shows HCs from a whole-mount surface preparation of the adult cochlea ( P120). Cochlear positions transmitting sound at 12 and $27 \mathrm{kHz}$ were calculated using a mouse frequency-place map (Müller et al., 2005). There is no $\mathrm{HC}$ loss at 12 and $27 \mathrm{kHz}$ positions in WT $(\boldsymbol{A})$, ML1KO (B), and ML3KO ( $)$ cochleae. However, OHC loss can be observed in DKO (D) and CDKO (E) cochleae (asterisks). The extent of OHC loss is more severe at the $27 \mathrm{kHz}$ position. No IHC loss was observed at either position. $\boldsymbol{F}$, Cytocochleograms showing $\% 0 \mathrm{HC}$ and $\% \mathrm{lHC}$ loss along the cochlear spiral for all genotypes $(\boldsymbol{A}-\boldsymbol{E}) .{ }^{*} p=0.014 .{ }^{* *} p=0.009 .{ }^{* * *} p=0.0008 .{ }^{* * * *} p \leq 0.0001$. Arrowheads indicate positions corresponding to 12 and $27 \mathrm{kHz}$. Scale bars, $10 \mu \mathrm{m}$.

position is much greater than that at $\sim 12 \mathrm{kHz}$, which is consistent with the greater ABR and DPOAE threshold shifts at $27 \mathrm{kHz}$ (Fig. 1). Cytocochleograms also reveal that WT, ML1KO, and ML3KO mice display a loss of OHCs at the extreme base of the cochlea (Fig. 4F). This loss, accompanied by high-frequency hearing loss, is a characteristic of the C57BL/6 inbred strain (Parham, 1997; Spongr et al., 1997; Ison et al., 2007). Because all mice tested have a genetic background of C57BL/6 mixed with Sv129 and 129S6, and the ABR and DPOAE thresholds of the ML1KO and ML3KO mice do not differ from those of their WT littermates (Fig. 1A-D), their loss of OHCs at the extreme base is not attributed to the loss of mucolipins. However, the cytocochleograms of DKO and cDKO mice reveal a much greater OHC loss at more apical positions compared with littermate controls. In addition, the fact that there is no obvious IHC loss in DKO and CDKO mice agrees with their comparably raised DPOAE and ABR thresholds, which are characteristic of $\mathrm{OHC}$ dysfunction (Fig. $1 B-H)$. This pattern of OHC loss, from high (cochlear base) to low (cochlear apex) frequencies, is consistent with the pattern of hearing loss observed (Fig. 1). Finally, the extent of OHC loss was virtually identical between DKO and cDKO mice, which demonstrates that the cause of $\mathrm{OHC}$ degeneration is the coabsence of mucolipins 3 and 1 in HCs, and not in strial cells (Fig. 4F).
Lysosomes in OHCs lacking mucolipins 3 and 1 are enlarged Because mucolipins are lysosomal channels, we examined these organelles using immunohistochemistry for the lysosomal marker LAMP1. First, we found that DKO OHCs have enhanced LAMP1 immunoreactivity compared with control OHCs (Fig. 5A,B). When comparing whole-cell LAMP1 fluorescence from immunohistochemistry on frozen cochlear sections, DKO OHCs have 3.7-fold higher LAMP1 immunoreactivity than those from control cochleae (Fig. 5C: WT, $6656 \pm 2561$ arbitrary units of fluorescent intensity [AU]; ML1KO, $5730 \pm 2166$ AU; ML3KO, $7721 \pm 2063$ AU; DKO, 30,793 \pm 6917 AU). This lysosomal enrichment in DKO OHCs was not dependent on their position along the length of the cochlea, as we did not observe differences in LAMP1 staining in OHCs from middle, apical-middle, or apical turns (Fig. 5D). Hence, to further explore the subcellular basis of ARHL in DKO mice, we consistently examined OHCs from middle cochlear turns, which approximately correspond to $25 \%$ $75 \%$ distance from the cochlear apex, and hence to the area of OHC loss (Fig. 4F).

The lysosomal (LAMP1) increase in DKO OHCs was not homogeneous throughout the cells but concentrated at their most apical third. At the basal third (0\%-33\% distance from the nucleus) of the cell, DKO OHC contained approximately the same 
A LAMP1 + DAPI, radial section, middle turn

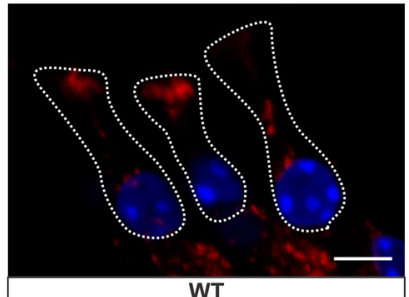

WT

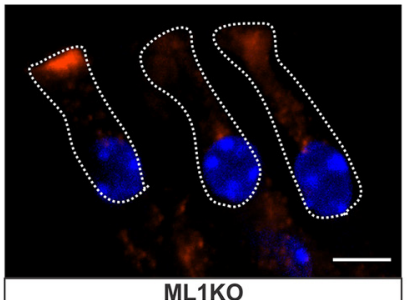

ML1KO

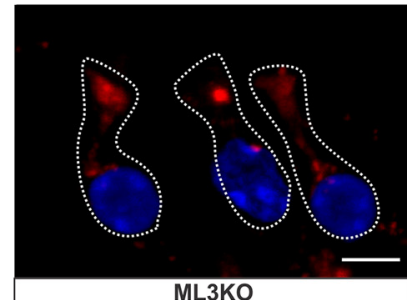

ML3KO

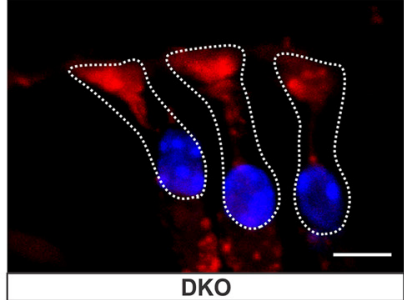

DKO

B LAMP1 + Actin, whole mount, middle turn, row 2
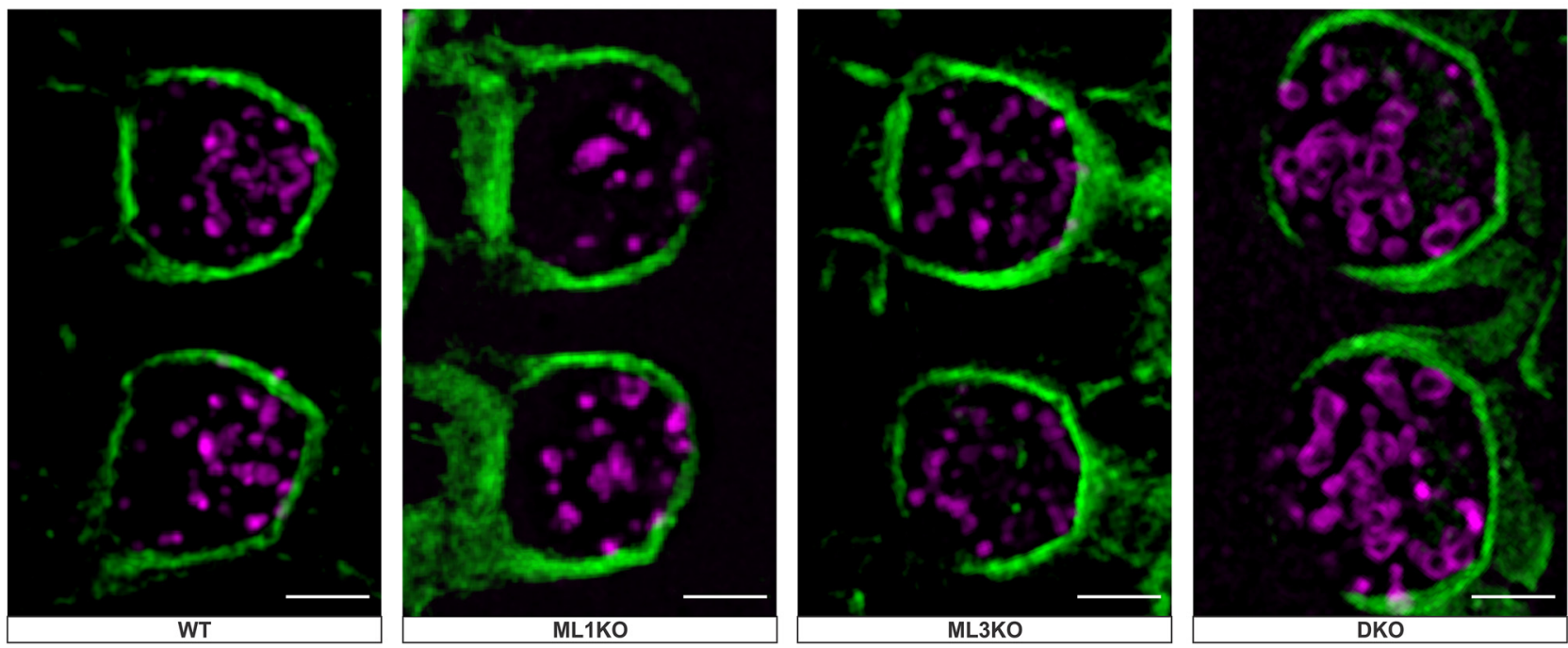

C

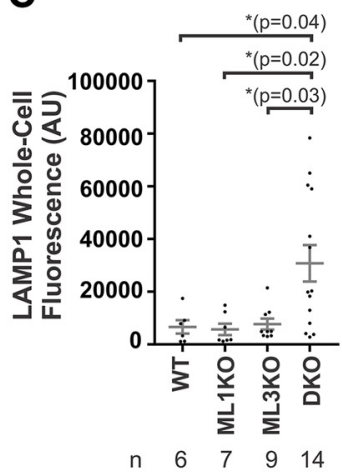

$\begin{array}{lllll}\text { \#Cells } & 39 & 45 & 43 & 60\end{array}$

$\mathbf{E}$

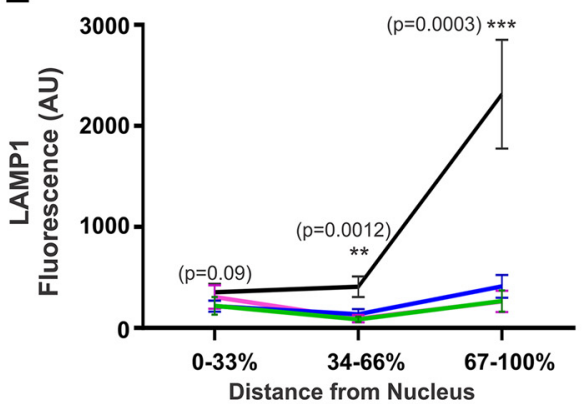

- WT ( $n=6 ; 39$ cells)

- ML1KO ( $n=6 ; 45$ cells)

- ML3KO ( $n=9 ; 43$ cells)

- DKO ( $n=14 ; 60$ cells)

D

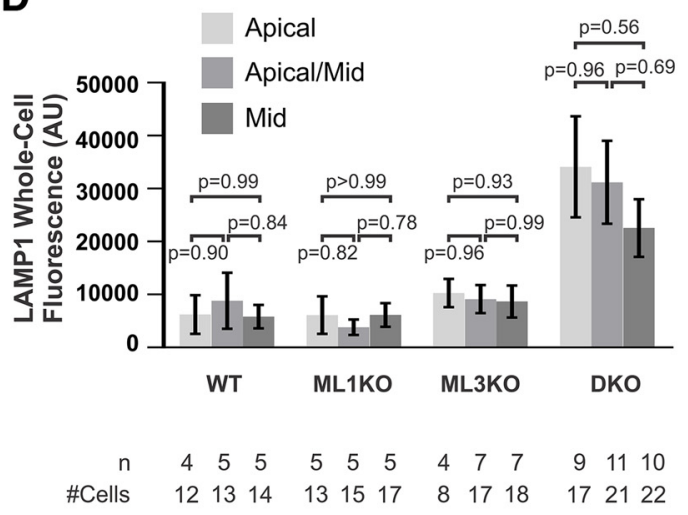

$\mathbf{F}$

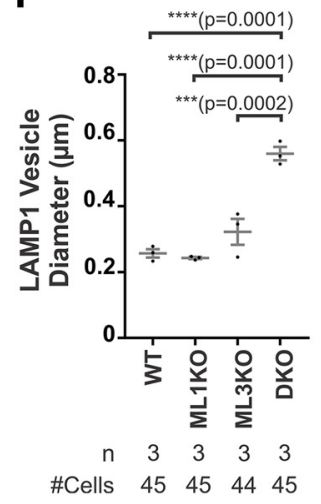

G

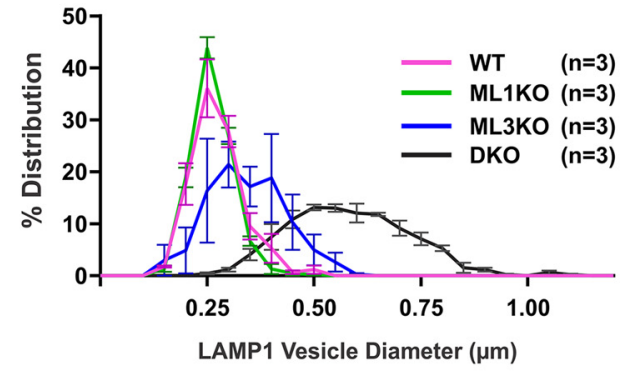

Figure 5. OHCs lacking mucolipins 3 and 1 possess pathologically enlarged lysosomes. $A$, Immunoreactivity of LAMP1 (a lysosomal membrane protein) in adult ( $\sim P 120) 0 H C s$ reveals apical accumulation of lysosomes in DKO OHCs but not in those from WT, ML1KO, and ML3KO control cochleae. B, Super-resolution structured illumination microscopy shows that DKO OHCs, but not the controls, possess enlarged lysosomes as indicated by LAMP1 immunoreactivity. $\boldsymbol{B}$, Images were $0 H C$ from row 2 . C, Quantification of total whole-cell LAMP1 fluorescence from $A$ reveals a significant increase in LAMP1 in DKO OHCs but not in control cochleae. D, LAMP1 whole-cell intensity values used in C are replotted separately based on cochlear position (Figure legend continues.) 
amount of LAMP1 immunofluorescence as control OHCs (Fig. 5E: WT, $3086 \pm 1174 \mathrm{AU}$; ML1KO, $2202 \pm 887$ AU; ML3KO, $2268 \pm 554$ AU; DKO, $3560 \pm 851 \mathrm{AU})$. There was a slight increase in overall LAMP1 at the middle third $(34 \%-66 \%$ distance from the nucleus) of DKO OHC (Fig. 5E: WT, $943 \pm 384$ $\mathrm{AU}$; ML1KO, $845 \pm 278 \mathrm{AU}$; ML3KO, $1381 \pm 509 \mathrm{AU} ; \mathrm{DKO}$, $4094 \pm 1019$ AU). However, there was a striking increase of LAMP1 fluorescence at the apical third portion of DKO OHCs (Fig. 5E: WT, $2621 \pm 1087 \mathrm{AU}$; ML1KO, $2683 \pm 1070 \mathrm{AU}$; ML3KO, $4119 \pm 1143$ AU; DKO, 23,139 \pm 5397 AU).

The increase on LAMP1 immunoreactivity could be due to an increase in LAMP1 protein concentration in lysosome membranes, in the number of lysosomes, or in their size. To more accurately visualize lysosomes in OHCs, we performed LAMP1 immunohistochemistry on whole-mount surface preparations of the organ of Corti (which affords better preservation of cellular structures that frozen sections) and imaged them with superresolution structured illumination microscopy. Because LAMP1 localizes to the membrane of lysosomes, we used its immunofluorescence to measure lysosomal size. To facilitate comparisons, we used the same criteria for selection of representative lysosomes for measurements in control and DKO OHCs: (1) we only selected lysosomes that were visibly isolated as the microscope could not resolve objects closer than $\sim 100 \mathrm{~nm}$; and (2) we only measured lysosomal diameter using the optical plane that yielded the largest diameter because we found lysosomes to be approximately spherical. Our examinations indicate that lysosomes (LAMP1-positive vesicles) were larger in OHCs from DKO cochleae than those from the controls (Fig. $5 B$ ). Specifically, lysosomes from DKO OHCs had a 2.18-fold larger diameter than those measured from control OHCs (Fig. 5 B, F: WT, $0.257 \pm 0.01$ $\mu \mathrm{m} ; \mathrm{ML} 1 \mathrm{KO}, 0.243 \pm 0.003 \mu \mathrm{m} ; \mathrm{ML} 3 \mathrm{KO}, 0.322 \pm 0.04 \mu \mathrm{m}$; $\mathrm{DKO}, 0.560 \pm 0.02 \mu \mathrm{m})$. Increasing lysosomal diameter by 2.18 fold (from WT to DKO) would result in a 4.75 -fold increase in lysosomal surface area, which accounts for the 4.63-fold increase in LAMP1 immunoreactivity, as it is a lysosomal membrane marker (Fig. 5C). Moreover, we found that DKO OHCs not only have larger lysosomes $(\sim 0.25-0.8 \mu \mathrm{m})$ but also fewer smaller ones $(\sim 0.15-0.4 \mu \mathrm{m})$, of the size typically found in control OHCs (Fig. $5 G$ ). Our results suggest that the increase in overall LAMP1 fluorescence observed in mucolipin-codeficient OHCs (Fig. $5 A, C)$ is not due to an increase in the number of lysosomes or in the density of LAMP1 protein, but to an increase in the size of the lysosomes.

\section{Autophagy, mitophagy, and pexophagy appear unaltered in mucolipin-codeficient OHCs}

Lysosomal defects have been shown to lead to cytotoxicity in two ways. One is by a failing to degrade damaged organelles (e.g., mitochondria or peroxisomes) that have become toxic, a process generally performed through autophagy (Raben et al., 2009; Jegga et al., 2011; Button et al., 2017). Another way lysosomes can harm cells is by becoming toxic themselves, a process involving

$\leftarrow$

(Figure legend continued.) (apical, apical/middle, and middle). We observed no difference in OHC LAMP1 intensity between cochlear turns within each genotype. $\boldsymbol{E}$, LAMP1 intensity values used in $\mathrm{C}$ are replotted, binning the apical-basal axis of OHCs in three segments based on the percentage distance from the nucleus. $\boldsymbol{F}$, By measuring LAMP1 vesicle diameter from images taken from confocal and structured illumination microscopy, we found that lysosomal diameter of DKO OHCs is $\sim 2.18$-fold larger than that from control $\mathrm{OHCS}$. G, A frequency distribution plot of LAMP1 vesicle diameter in all genotypes. Scale bars: $\boldsymbol{A}, 5 \mu \mathrm{m} ; \boldsymbol{B}, 2 \mu \mathrm{m} .{ }^{*} p<0.05$; ${ }^{* *} p<$ $0.01 ;{ }^{* * *} p<0.001 ;{ }^{* * *} p \leq 0.0001$ permeabilization of their membranes (Boya and Kroemer, 2008; Oku et al., 2017). Lysosomes harbor within their lumens hydrolytic enzymes that would be harmful if released into the cytosol. We explored whether either of these mechanisms could account for the $\mathrm{OHC}$ degeneration caused by mucolipin codeficiency. Initially, we focused on organelles whose dysfunction causes OHC loss: peroxisomes (Delmaghani et al., 2015) and mitochondria (Chen and Tang, 2014; Seo et al., 2017). These organelles have a limited lifespan and, when damaged, are removed by lysosomes through the processes of pexophagy and mytophagy. If these processes were impaired, we would expect an increase in the number of such organelles.

Because dysfunctional and/or damaged peroxisomes can increase sensitivity to noise-induced hearing loss, even at neonatal stages (Delmaghani et al., 2015), we used a peroxisomal marker PMP70 to examine whether there was any peroxisomal accumulation or defect in DKO OHCs (Fig. 6A,D,E). Both control and $\mathrm{DKO} \mathrm{OHCs}$ had similar numbers of peroxisomes per cell (Fig. 6D: WT, $5.32 \pm 0.42 ; \mathrm{ML} 1 \mathrm{KO}, 4.73 \pm 0.45 ; \mathrm{ML} 3 \mathrm{KO}, 6.16 \pm 0.64$; $\mathrm{DKO}, 5.26 \pm 0.73$ ), and the peroxisomes were of similar size (Fig. $6 E$ : WT, $0.289 \pm 0.024 \mu \mathrm{m}^{3} ; \mathrm{ML} 1 \mathrm{KO}, 0.225 \pm 0.015 \mu \mathrm{m}^{3}$; $\mathrm{ML} 3 \mathrm{KO}, 0.282 \pm 0.040 \mu \mathrm{m}^{3}$; DKO, $\left.0.204 \pm 0.01 \mu \mathrm{m}^{3}\right)$. Hence, we did not detect peroxisomal abnormalities in mucolipin-codeficient $\mathrm{OHCs}$.

Because defects in mitochondrial physiology can cause HC death (Fischel-Ghodsian et al., 1997; Chen and Tang, 2014), we examined whether there was any mitochondrial defect in $\mathrm{DKO}$ $\mathrm{OHCs}$ using antibodies to the mitochondrial cytochrome $\mathrm{C}$ oxidase subunit IV (COXIV) (Fig. 6B). COXIV immunoreactivity was strong and dense along the OHC's basolateral membrane and under the apical cuticular plate (Fig. 6B). Because mitochondria exist in a range of shapes and sizes from tubular to fragmented (Westermann, 2012), our confocal imaging could not quantify the number of these organelles. We therefore examined wholecell intensity of COXIV immunoreactivity in individual OHCs as an indirect way to determine whether there was mitochondrial accumulation. Similar to the PMP70 immunostaining, we did not detect any difference in COXIV whole-cell fluorescence in DKO OHCs compared with controls (Fig. 6F: WT, 170,385 \pm

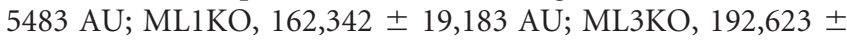
44,740 AU; DKO, 178,165 \pm 34,829 AU).

Lysosomes degrade these and other damaged organelles via autophagy, a process in which a double membrane encircles the cellular components to be degraded, forming an autophagosome that fuses with the lysosome. Because defects in autophagy have also been found to promote ARHL and HC degeneration (Fujimoto et al., 2017), we used immunoreactivity to LC3 to visualize autophagosomes. Although LC3 exists in a diffuse cytosolic form, it will coalesce on autophagosome membranes, giving a punctate pattern (Mizushima, 2009). We found that there was no increase or decrease in autophagosomes in DKO OHCs as indicated by the number of LC3 puncta (Fig. 6C,G,H). Specifically, both control and DKO OHCs have $\sim 14$ autophagosomes per cell (Fig. 6G: WT, $13.98 \pm 1.85 ; \mathrm{ML} 1 \mathrm{KO}, 15.73 \pm 0.78$; ML3KO, $15.22 \pm 1.32$; $\mathrm{DKO}, 13.50 \pm 1.16)$. We also noted no alteration in the volume of autophagosomes, which is $\sim 0.1 \mu^{3}$ (Fig. $6 \mathrm{H}$ : WT, $0.104 \pm$ $0.030 \mu \mathrm{m}^{3}$; ML1KO, $0.098 \pm 0.031 \mu \mathrm{m}^{3}$; ML3KO, $0.141 \pm 0.014$ $\mu \mathrm{m}^{3}$; DKO, $0.103 \pm 0.030 \mu \mathrm{m}^{3}$ ).

In conclusion, we detected no aberrant accumulation (or decrease) of autophagosomes, peroxisomes, or mitochondria in OHC lacking mucolipins 3 and 1, as would be expected if lysosomes failed to perform the intracellular digestion of damaged organelles. 


\section{A PMP70 + Actin}
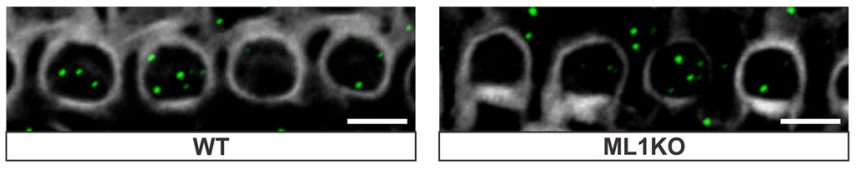

B coxIV + Actin
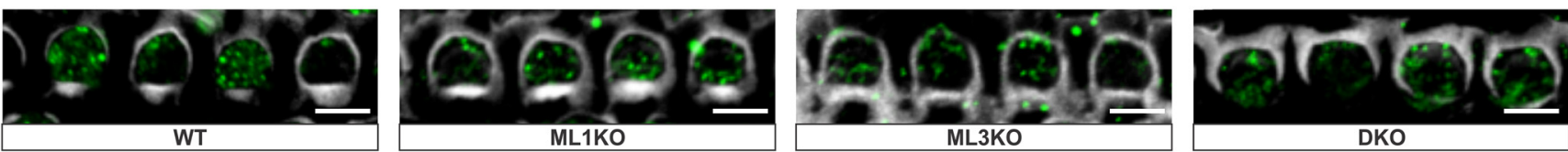

C LC3 + Actin
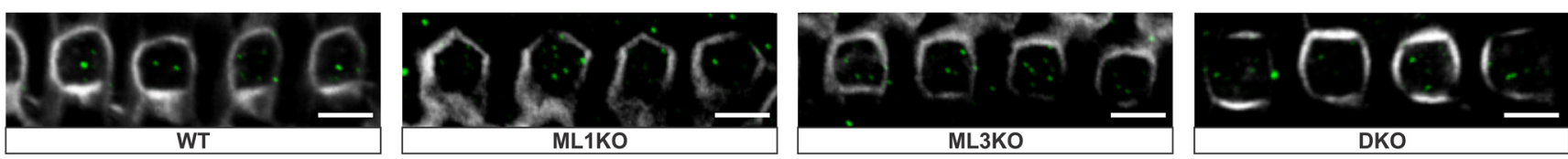

D

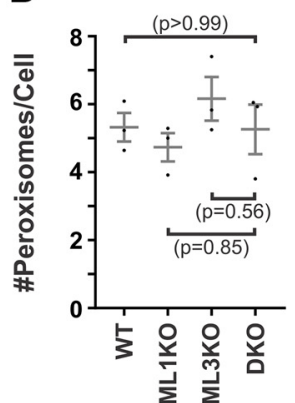

E

$\mathbf{F}$

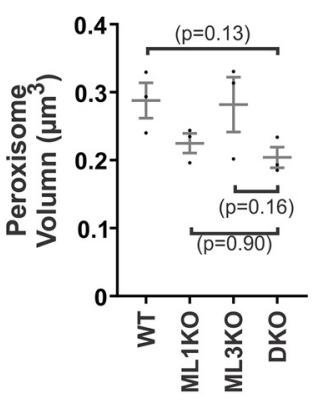

$\begin{array}{lllll}\mathrm{n} & 3 & 3 & 3 & 3\end{array}$

\#Cells 122138135122

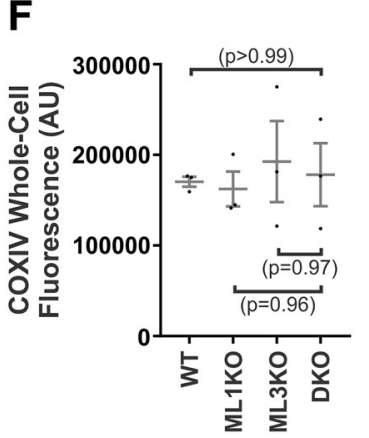

$\begin{array}{lllll}n & 3 & 3 & 3 & 3\end{array}$

\#Cells $45 \quad 45 \quad 45 \quad 45$
G

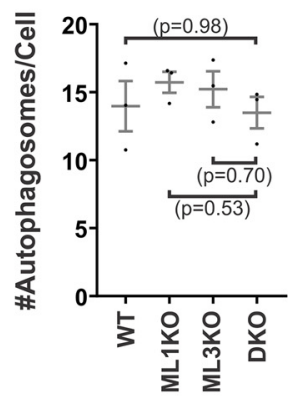

$\begin{array}{lllll}n & 3 & 3 & 3 & 3\end{array}$

\#Cells 120121136131
H

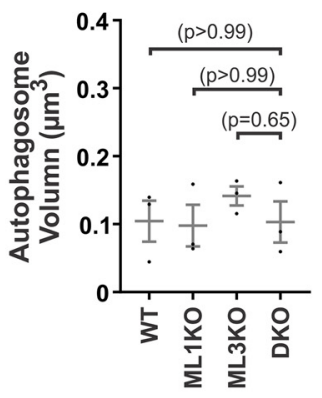

$\begin{array}{lllll}n & 3 & 3 & 3 & 3\end{array}$

\#Cells 120121136131

Figure 6. Enlarged lysosomes in OHCs lacking mucolipin 3 and 1 do not cause defects in lysosomal degradation of damaged organelles. A-C, Whole-mount cochleae from WT, ML1KO, ML3KO, and DK0 adult ( $\sim P 120)$ animals using different organelle markers: peroxisome (PMP70, $A)$, mitochondria (COXIV, $B$ ), and autophagosome (LC3, $C$ ). There is no apparent defect in distributions and numbers of peroxisomes $(\boldsymbol{A})$, mitochondria $(\boldsymbol{B})$, and autophagosomes $(\boldsymbol{C})$. Representative images were reconstructed from a projection of 8 confocal optical sections spanning $0.88 \mu \mathrm{m}$ under the cuticular plate. $\boldsymbol{D}, \boldsymbol{E}$, The number of peroxisomes per $\mathrm{OHC}$ and peroxisomal volume, indicated by PMP70 immunoreactivity, from DKO OHCs are similar to those from controls. $\boldsymbol{F}$, Whole-cell fluorescence of COXIV did not differ between DKO and contro OHCS. $\mathbf{G}, \boldsymbol{H}$, The number of autophagosomes per $\mathrm{OHC}$ and autophagosomal volume, indicated by LC3 immunoreactivity, from DKO OHCs are similar to controls. Scale bars, $5 \mu \mathrm{m}$.

\section{Lysosomes in OHCs lacking mucolipins 3 and 1 are permeabilized}

Lysosomal membrane permeabilization can trigger multiple cell death pathways, presumably due to the release into the cytosol of the hydrolytic enzymes normally safely retained within the lumen of the organelle (Brunk et al., 1997; Ono et al., 2003; Boya and Kroemer, 2008; Aits et al., 2015). Because larger lysosomes are more susceptible to lysosomal membrane permeabilization (Ono et al., 2003), we examined lysosomal integrity in OHCs using the galectin 3 assay as an indicator of lysosomal membrane permeabilization (Aits et al., 2015). Galectin 3 is a cytosolic lectin with high binding affinity to the glycocalyx located on the luminal surface of lysosomes. Because galectin 3 is impermeable to membranes, it does not normally localize to the lumen of lysosomes. However, if the lysosomal membrane is compromised, galectin 3 translocates to the lumen. Indeed, we observed puncta of galectin 3 immunoreactivity in DKO OHCs associated with lysosomes, as indicated by a double-staining of LAMP1 and galectin 3 (Fig. $7 D$ ), whereas the galectin 3 signal in control OHCs was cytosolic (Fig. 7A-C). In addition, super-resolution structured illumination microscopy reveals that galectin 3 is surrounded by the lysosomal membrane marker LAMP1 and, therefore, localized to the lysosomal lumen (Fig. 7E).
An expected consequence of lysosomal membrane permeabilization would be the release of hydrolytic enzymes from the lysosomal lumen to the cytosol. In the controls, cathepsin D is localized to the lysosomal lumen, as indicated by its association with LAMP1 immunoreactivity (Fig. $7 F-H$ ). Conversely, in DKO $\mathrm{OHCs}$, most of the enlarged lysosomes contain undetectable to low levels of cathepsin D (Fig. 7I). The absence of cathepsin D in DKO lysosomes is consistent with the presence of galectin 3 in the lysosomal lumen, confirming that the lysosomal membrane is permeabilized in DKO. Although we could not detect cathepsin in the cytosol of DKO OHCs, we reason that its vastly larger volume dilutes cathepsin D below the level of detection. Altogether, mucolipin-codeficient lysosomes have permeabilized membranes, a condition known to cause the release of toxic hydrolases into the cytosol (Boya and Kroemer, 2008; Li et al., 2016; Oku et al., 2017).

\section{Discussion}

Although lysosomal defects have been noted to cause hearing loss (Ohlemiller et al., 2002; Heldermon et al., 2007; Schachern et al., 2007), our findings implicate HC lysosomes for the first time in ARHL and HC degeneration. In the case of mucopolysaccharidosis I (Schachern et al., 2007) and mucopolysaccharidosis IIIB 
A WT (Galectin3 + LAMP1 + Actin)
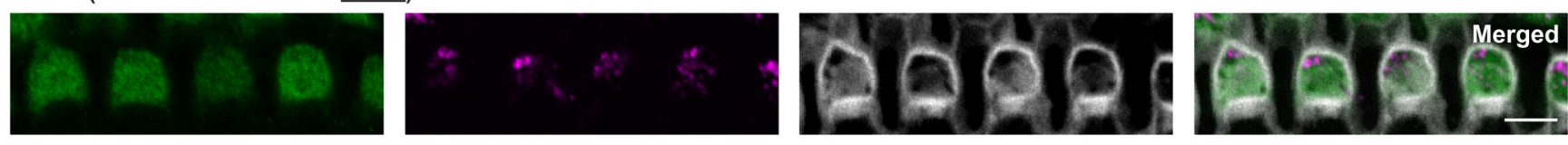

\section{B ML1KO (Galectin3 + LAMP1 + Actin)}
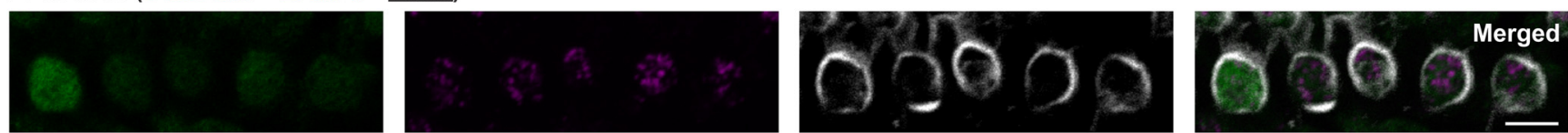

\section{ML3KO (Galectin3 + LAMP1 + Actin)}
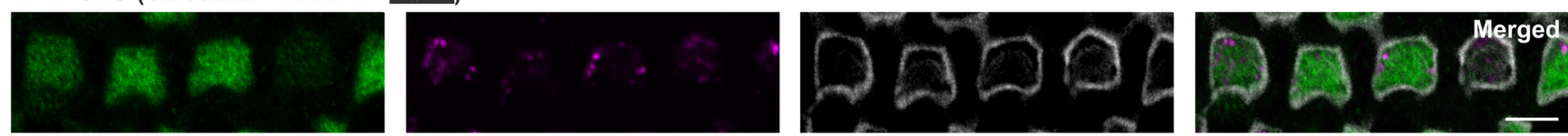

\section{DKo (Galectin3 + LAMP1 + Actin)}
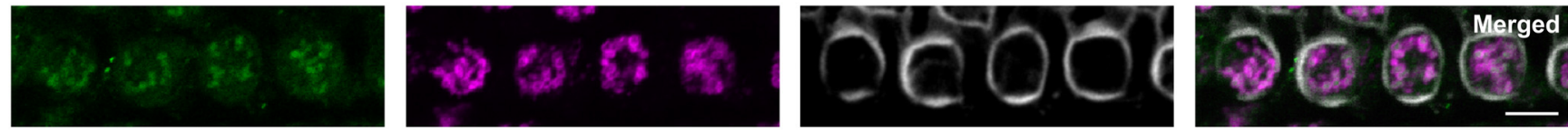

\section{EDKO (Galectin3 + LAMP1 + Actin)}
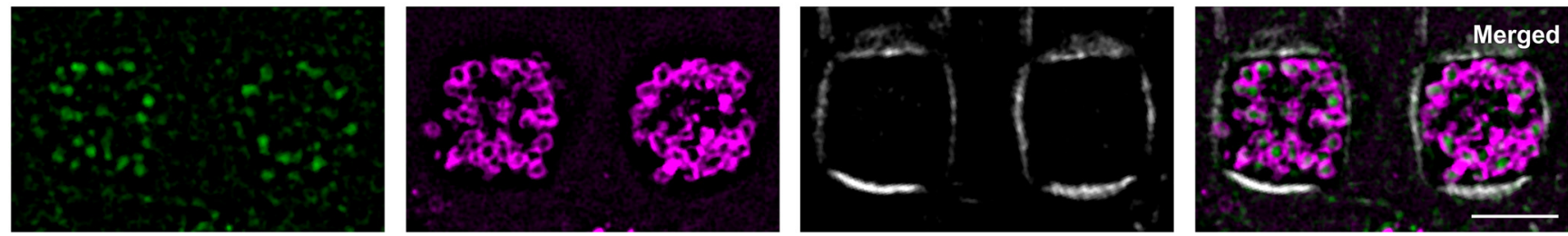

$\mathbf{F}_{\text {WT }}$ (Cathepsin D + LAMP1 + Actin)
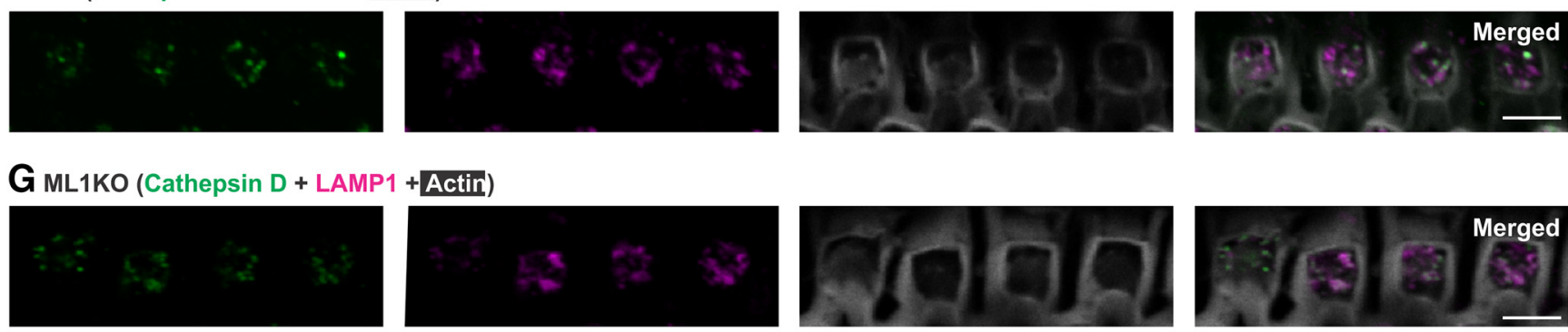

H ML3KO (Cathepsin D + LAMP1 + Actin)
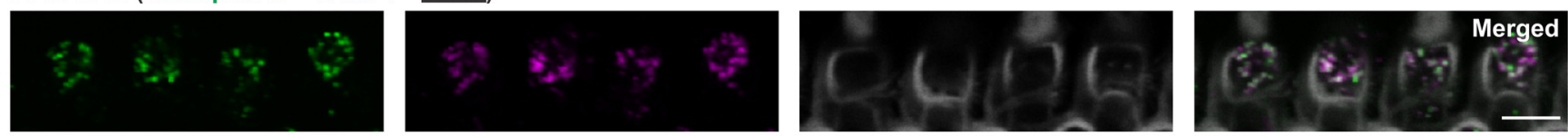

\section{DKO (Cathepsin D + LAMP1 + Actin)}
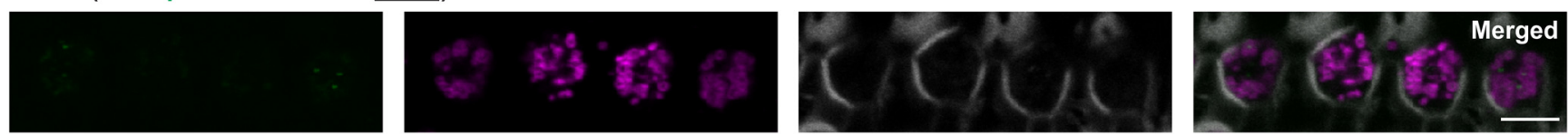

Figure 7. OHCs lacking mucolipin 3 and 1 exhibit lysosomal membrane permeabilization. $A-D$, Immunoreactivity of galectin 3 , a membrane-impermeable cytosolic lectin with high affinity for the luminal lysosomal glycocalyx (Aits et al., 2015), and LAMP1 reveal that lysosomal membranes in DKO OHCs are permeabilized. Galectin 3 is cytosolic in WT (A), ML1KO (B), and ML3KO (C) OHCS, and its expression level varied. $\boldsymbol{D}$, In contrast, galectin 3 immunoreactivity has a vesicular pattern that is associated with LAMP1 signal in DKO OHCs. E, Super-resolution-structured illumination microscopy shows that galectin 3 is localized to lysosomal lumen. $\boldsymbol{F}-\mathbf{I}$, Immunoreactivity of cathepsin D and LAMP1 reveals that, upon lysosomal permeabilization, DKO lysosomes contain very low levels of cathepsin D. Cathepsin D has a vesicular expression pattern strongly associated with lysosomes in WT (F), ML1KO (G), and ML3KO (H) OHCs. II, In contrast, cathepsin D levels are low or undetectable in DKO lysosomes. Samples were from adult ( P120) animals. Scale bars: $A-D, F-I, 5 \mu \mathrm{m} ; \boldsymbol{E}, 2 \mu \mathrm{m}$. 
(Heldermon et al., 2007), deafness includes loss of both HCs and supporting cells of the organ of Corti. However, because lysosomal vacuolation was not detected in HCs but was found prominently in supporting cells, defective HC lysosomes were not considered the cause of HC degeneration and deafness. These studies, however, did not selectively ablate lysosomal genes in $\mathrm{HCs}$, as we did here to reveal that the source of HC loss was cell autonomous and not due to defects in supporting cells.

The genetic and subcellular bases of ARHL have proven arduous to uncover (Ohlemiller, 2006; Liberman, 2017). By using transgenic mouse models with codeficiency of lysosomal mucolipins 3 and 1 in HCs, we found a novel, polygenic cause for early-onset ARHL accompanied by OHC loss. Our findings implicate two new genes, Trpml1 and Trpml3, adding to the exiguous list of genes that participate in the complex pathologies associated with presbycusis. This hearing loss phenotype is polygenic because of the redundancy between Trpmll and Trpml3. It is unclear why HCs would require both mucolipins to maintain their longevity because there is no hearing phenotype or HC degeneration in mice lacking either mucolipin alone (Jörs et al., 2010). However, this redundancy also occurs in neonatal intestinal enterocytes where a pathology was observed in DKO mice, but not in ML1KO and ML3KO mice (Remis et al., 2014). As with other cases of genetic redundancy, it is possible that mucolipin 3 serves a subtle lysosomal function that we can only detect in the absence of mucolipin 1. Nonetheless, and although we did not detect any enhanced ARHL even in aged (8-month-old) ML3KO mice (data not shown), we should not rule out the possibility that in the much longer lifespan of decades mucolipin 3 deficiency might predispose humans to an earlier onset ARHL.

While mucolipin 1 is expressed in lysosomes of all cell types (Bach, 2001; LaPlante et al., 2002; Bach et al., 2005), mucolipin 3 is expressed in only a small subset of cells (Nagata et al., 2008; Remis et al., 2014). This restricted expression suggests that cells expressing mucolipin 3 may have specialized lysosomes. Indeed, mucolipin 3-expressing neonatal intestinal enterocytes have giant lysosomes dedicated to the intracellular digestion of endocytosed proteins from maternal milk (Remis et al., 2014). Mucolipin 3-expressing melanocytes produce melanosomes from specialized premelanosomal lysosomes (Raposo and Marks, 2002; Schiaffino, 2010); and marginal cells of the stria vascularis, which also express mucolipin 3 (Nagata et al., 2008), use lysosomes to localize potassium KCNQ1 channels to their apical membranes (Knipper et al., 2006). Hence, it seems reasonable to hypothesize that HCs, expressing mucolipin 3, may also have specialized lysosomes.

Our original hypothesis was that HCs have specialized lysosomes for self-repair and maintenance, and hence for their ability to survive in a challenging environment for a very long time (in many cases for as long as the lifetime of the organism). Although the loss of OHCs due to mucolipin codeficiency favored this hypothesis, we found no evidence that in these OHCs the lysosome-mediated repair mechanisms (autophagy, mitophagy, and pexophagy) are compromised (Fig. 6). Although the hypothesis that HCs contain specialized lysosomes dedicated to a self-repair required for their remarkable longevity is still valid, this is not the reason for $\mathrm{OHC}$ loss due to mucolipin codeficiency. Instead, we reveal another mechanism by which OHC vulnerability may be increased: swelling and permeabilization of lysosomes, which would lead to the release of lysosomal hydrolases into the cytosol (Fig. 7). Studies have shown that lysosomal enlargement is a common event preceding cell death, and that enlarged lysosomes are vulnerable to lysosomal membrane permeabilization (Ono et al.,
2001, 2003). Lysosomal membrane permeabilization causes leakage of luminal contents into the cytosol, including the smaller of the $\sim 50$ types of hydrolytic enzymes (Schröder et al., 2010), which can trigger cell death through apoptosis or necrosis (Boya and Kroemer, 2008; Repnik et al., 2014; Li et al., 2016). Accordingly, we noted a depletion of cathepsin $\mathrm{D}$, one of the smaller hydrolases, from mucolipin-codeficient lysosomes (Fig. 7I). This depletion of cathepsin D does not seem to impair the overall function of the lysosomes (at least in regards to pexophagy, mitophagy, and autophagy; Fig. 6), presumably because they retain most of their (larger) hydrolases (Schröder et al., 2010; Repnik et al., 2014).

Causes of lysosomal membrane permeabilization include osmotic lysis and direct membrane lysis by surfactant activity (Repnik et al., 2014). In our case, lysosomal membrane permeabilization might be due to increased luminal osmotic pressure, as lysosomes lacking mucolipin 3 and 1 are abnormally large (Fig. 5).

It is also of interest that lysosomal membrane permeabilization in OHCs lacking mucolipins is not immediately cytotoxic. OHCs survive with permeabilized lysosomes for weeks to months but in time perish along a base to apical gradient characteristic of OHC loss during ARHL. Hence, the toxic effects of lysosomal enlargement and permeabilization are to enhance the vulnerability of OHCs, whose degeneration ultimately depends on other factors related to age and position. The weak toxicity resulting from lysosomal permeabilization may be due to the $\mathrm{pH}$ dependence of lysosomal hydrolases, as they function best at the low $\mathrm{pH}$ of the lysosomal lumen and are much less active at cytosolic $\mathrm{pH}$ levels. While most lysosomal hydrolases are inactive at a neutral $\mathrm{pH}$, a family of lysosomal hydrolases, notably cathepsins $\mathrm{D}, \mathrm{L}$, and S, is known to be active in the cytosol (Lkhider et al., 2004; Vasiljeva et al., 2005; Jiang et al., 2006; Boya and Kroemer, 2008). While cathepsins eventually unfold, losing their hydrolytic properties, their preserved activities, even only for a matter of hours, is sufficient to induce cell death signaling (Turk et al., 2012). Because cathepsin represents a small subset of lysosomal enzymes (Schröder et al., 2010) and lysosomal content accounts for a small portion of total cytoplasmic volume, these lysosomal enzymes would be diluted in the cytosol of OHCs, rendering their hydrolytic activities gradual and cumulative, thereby leading to progressive OHC denegation in ARHL.

Mucolipins have been implicated in multiple aspects of lysosomal function. For example, both mucolipins 3 and 1 facilitate scission of the endolysosomal hybrid organelles in neonatal intestinal enterocytes (Remis et al., 2014), whereas mucolipin 1 facilitates lysosomal fusion to endosomes in macrophages (Thompson et al., 2007). Studies reported that mucolipins function in lysosomal exocytosis in different cell types. For instance, in a bladder epithelial cell line, mucolipin 3 facilitates lysosomal exocytosis for pathogen expulsion (Miao et al., 2015), whereas mucolipin 1 regulates lysosomal exocytosis as a part of plasma membrane repair in muscle fibers (Cheng et al., 2014). Here we report a novel role of mucolipins that affects lysosomal volume and lysosomal membrane integrity. Although we can only speculate as to the molecular steps leading to these organelle defects, one possibility is an increased lysosomal osmotic pressure due to cation accumulation. Because both mucolipin 3 and 1 are inwardly rectifying lysosomal cation channels, their absence would prevent cations from leaving the lysosome. Upon accumulation of luminal cations, the osmotic pressure would increase, ultimately leading to lysosomal membrane destabilization and permeabilization.

In conclusion, we identify a new mechanism by which toxic organelles, in our case lysosomes lacking mucolipin 3 and 1, 
could lead to premature OHC death and ARHL. We also demonstrate a novel role of mucolipin channels in sustaining lysosomal size and lysosomal membrane integrity. The discovery that mice lacking both lysosomal mucolipins 3 and 1 display accelerated ARHL due to OHC degeneration underscores the importance of lysosomes in long-term HC survival.

\section{References}

Aits S, Kricker J, Liu B, Ellegaard AM, Hämälistö S, Tvingsholm S, CorcelleTermeau E, Høgh S, Farkas T, Holm Jonassen A, Gromova I, Mortensen M, Jäättelä M (2015) Sensitive detection of lysosomal membrane permeabilization by lysosomal galectin puncta assay. Autophagy 11:14081424. CrossRef Medline

Bach G (2001) Mucolipidosis type IV. Mol Genet Metab 73:197-203. CrossRef Medline

Bach G, Webb MB, Bargal R, Zeigler M, Ekstein J (2005) The frequency of mucolipidosis type IV in the Ashkenazi Jewish population and the identification of 3 novel MCOLN1 mutations. Hum Mutat 26:591. CrossRef Medline

Boya P, Kroemer G (2008) Lysosomal membrane permeabilization in cell death. Oncogene 27:6434-6451. CrossRef Medline

Brunk UT, Dalen H, Roberg K, Hellquist HB (1997) Photo-oxidative disruption of lysosomal membranes causes apoptosis of cultured human fibroblasts. Free Radic Biol Med 23:616-626. CrossRef Medline

Button RW, Roberts SL, Willis TL, Hanemann CO, Luo S (2017) Accumulation of autophagosomes confers cytotoxicity. J Biol Chem 292:1359913614. CrossRef

Cable J, Steel KP (1998) Combined cochleo-saccular and neuroepithelial abnormalities in the Varitint-Waddler-J (VaJ) mouse. Hear Res 123:125136. CrossRef Medline

Castiglioni AJ, Remis NN, Flores EN, García-Añoveros J (2011) Expression and vesicular localization of mouse Trpml3 in stria vascularis, hair cells, and vomeronasal and olfactory receptor neurons. J Comp Neurol 519: 1095-1114. CrossRef Medline

Cheatham MA, Goodyear RJ, Homma K, Legan PK, Korchagina J, Naskar S, Siegel JH, Dallos P, Zheng J, Richardson GP (2014) Loss of the tectorial membrane protein CEACAM16 enhances spontaneous, stimulus-frequency, and transiently evoked otoacoustic emissions. J Neurosci 34:10325-10338. CrossRef Medline

Chen H, Tang J (2014) The role of mitochondria in age-related hearing loss. Biogerontology 15:13-19. CrossRef Medline

Cheng X, Zhang X, Gao Q, Ali Samie M, Azar M, Tsang WL, Dong L, Sahoo N, Li X, Zhuo Y, Garrity AG, Wang X, Ferrer M, Dowling J, Xu L, Han R, Xu $\mathrm{H}$ (2014) The intracellular $\mathrm{Ca}^{2+}$ channel MCOLN1 is required for sarcolemma repair to prevent muscular dystrophy. Nat Med 20:1187-1192. CrossRef Medline

Dallos P, Fakler B (2002) Prestin, a new type of motor protein. Nat Rev Mol Cell Biol 3:104-111. CrossRef Medline

Dannhof BJ, Bruns V (1993) The innervation of the organ of corti in the rat. Hear Res 66:8-22. CrossRef Medline

Delmaghani S, Defourny J, Aghaie A, Beurg M, Dulon D, Thelen N, Perfettini I, Zelles T, Aller M, Meyer A, Emptoz A, Giraudet F, Leibovici M, Dartevelle S, Soubigou G, Thiry M, Vizi ES, Safieddine S, Hardelin JP, Avan P, et al. (2015) Hypervulnerability to sound exposure through impaired adaptive proliferation of peroxisomes. Cell 163:894-906. CrossRef Medline

Di Palma F, Belyantseva IA, Kim HJ, Vogt TF, Kachar B, Noben-Trauth K (2002) Mutations in Mcoln3 associated with deafness and pigmentation defects in Varitint-Waddler (Va) mice. Proc Natl Acad Sci U S A 99: 14994-14999. CrossRef Medline

Fischel-Ghodsian N, Bykhovskaya Y, Taylor K, Kahen T, Cantor R, Ehrenman K, Smith R, Keithley E (1997) Temporal bone analysis of patients with presbycusis reveals high frequency of mitochondrial mutations. Hear Res 110:147-154. CrossRef Medline

Fujimoto C, Iwasaki S, Urata S, Morishita H, Sakamaki Y, Fujioka M, Kondo K, Mizushima N, Yamasoba T (2017) Autophagy is essential for hearing in mice. Cell Death Dis 8:e2780. CrossRef Medline

Gamp AC, Tanaka Y, Lüllmann-Rauch R, Wittke D, D’Hooge R, De Deyn PP, Moser T, Maier H, Hartmann D, Reiss K, Illert AL, von Figura K, Saftig P (2003) LIMP-2/LGP85 deficiency causes ureteric pelvic junction obstruction, deafness and peripheral neuropathy in mice. Hum Mol Genet 12:631-646. CrossRef Medline
García-Añoveros J, Wiwatpanit T (2014) TRPML2 and mucolipin evolution. Handb Exp Pharmacol 222:647-658. CrossRef Medline

Grimm C, Cuajungco MP, van Aken AF, Schnee M, Jörs S, Kros CJ, Ricci AJ, Heller S (2007) A helix-breaking mutation in TRPML3 leads to constitutive activity underlying deafness in the Varitint-Waddler mouse. Proc Natl Acad Sci U S A 104:19583-19588. CrossRef Medline

Heldermon CD, Hennig AK, Ohlemiller KK, Ogilvie JM, Herzog ED, Breidenbach A, Vogler C, Wozniak DF, Sands MS (2007) Development of sensory, motor and behavioral deficits in the murine model of Sanfilippo syndrome type B. PLoS One 2:e772. CrossRef Medline

Ison JR, Allen PD, O’Neill WE (2007) Age-related hearing loss in C57BL/6J mice has both frequency-specific and non-frequency-specific components that produce a hyperacusis-like exaggeration of the acoustic startle reflex. J Assoc Res Otolaryngol 8:539-550. CrossRef Medline

Jegga AG, Schneider L, Ouyang X, Zhang J (2011) Systems biology of the autophagy-lysosomal pathway. Autophagy 7:477-489. CrossRef

Jiang H, Sha SH, Forge A, Schacht J (2006) Caspase-independent pathways of hair cell death induced by kanamycin in vivo. Cell Death Differ 13:2030. CrossRef Medline

Jörs S, Grimm C, Becker L, Heller S (2010) Genetic inactivation of Trpml3 does not lead to hearing and vestibular impairment in mice. PLoS One 5:e14317. CrossRef Medline

Keller JM, Neely HR, Latoche JR, Noben-Trauth K (2011) High-frequency sensorineural hearing loss and its underlying genetics (Hfhll and Hfhl2) in NIH Swiss mice. J Assoc Res Otolaryngol 12:617-631. CrossRef Medline

Kim HJ, Li Q, Tjon-Kon-Sang S, So I, Kiselyov K, Muallem S (2007) Gainof-function mutation in TRPML3 causes the mouse Varitint-Waddler phenotype. J Biol Chem 282:36138-36142. CrossRef Medline

Knipper M, Claussen C, Rüttiger L, Zimmermann U, Lüllmann-Rauch R, Eskelinen EL, Schröder J, Schwake M, Saftig P (2006) Deafness in LIMP2-deficient mice due to early loss of the potassium channel KCNQ1/ KCNE1 in marginal cells of the stria vascularis. J Physiol 576:73-86. CrossRef Medline

LaPlante JM, Falardeau J, Sun M, Kanazirska M, Brown EM, Slaugenhaupt SA, Vassilev PM (2002) Identification and characterization of the single channel function of human mucolipin-1 implicated in mucolipidosis type IV, a disorder affecting the lysosomal pathway. FEBS Lett 532:183187. CrossRef Medline

Li Y, Chen B, Zou W, Wang X, Wu Y, Zhao D, Sun Y, Liu Y, Chen L, Miao L, Yang C, Wang X (2016) The lysosomal membrane protein SCAV-3 maintains lysosome integrity and adult longevity. J Cell Biol 215:167-185. CrossRef Medline

Liberman MC (2017) Noise-induced and age-related hearing loss: new perspectives and potential therapies [version 1; referees: 4 approved]. F1000Res 6:927. CrossRef Medline

Lkhider M, Castino R, Bouguyon E, Isidoro C, Ollivier-Bousquet M (2004) Cathepsin D released by lactating rat mammary epithelial cells is involved in prolactin cleavage under physiological conditions. J Cell Sci 117:51555164. CrossRef Medline

Martin GK, Stagner BB, Lonsbury-Martin BL (2006) Assessment of cochlear function in mice: distortion-product otoacoustic emissions. Curr Protoc Neurosci 8:8.21C. CrossRef Medline

Miao Y, Li G, Zhang X, Xu H, Abraham SN (2015) A TRP channel senses lysosome neutralization by pathogens to trigger their expulsion. Cell 161: 1306-1319. CrossRef Medline

Micsenyi MC, Dobrenis K, Stephney G, Pickel J, Vanier MT, Slaugenhaupt SA, Walkley SU (2009) Neuropathology of the Mcoln1(-/-) knockout mouse model of mucolipidosis type IV. J Neuropathol Exp Neurol 68: 125-135. CrossRef Medline

Mizushima N (2009) Methods for monitoring autophagy using GFP-LC3 transgenic mice. In: Autophagy in mammalian systems: B, pp 13-23 Methods in enzymology. Amsterdam, the Netherlands: Elsevier.

Montell C (2005) The TRP superfamily of cation channels. Sci STKE 2005: re3. CrossRef Medline

Montgomery SC, Cox BC (2016) Whole mount dissection and immunofluorescence of the adult mouse cochlea. J Vis Exp 1:107. CrossRef Medline

Müller M, von Hünerbein K, Hoidis S, Smolders JW (2005) A physiological place-frequency map of the cochlea in the CBA/J mouse. Hear Res 202: 63-73. CrossRef Medline

Nagata K, Zheng L, Madathany T, Castiglioni AJ, Bartles JR, García-Añoveros J (2008) The Varitint-Waddler (Va) deafness mutation in TRPML3 gen- 
erates constitutive, inward rectifying currents and causes cell degeneration. Proc Natl Acad Sci U S A 105:353-358. CrossRef Medline

Noben-Trauth K, Zheng QY, Johnson KR (2003) Association of cadherin 23 with polygenic inheritance and genetic modification of sensorineural hearing loss. Nat Genet 35:21-23. CrossRef Medline

Noguchi Y, Kurima K, Makishima T, de Angelis MH, Fuchs H, Frolenkov G, Kitamura K, Griffith AJ (2006) Multiple quantitative trait loci modify cochlear hair cell degeneration in the beethoven (TmclBth) mouse model of progressive hearing loss DFNA36. Genetics 173:2111-2119. CrossRef Medline

Ohlemiller KK (2006) Contributions of mouse models to understanding of age- and noise-related hearing loss. Brain Res 1091:89-102. CrossRef Medline

Ohlemiller KK, Hennig AK, Lett JM, Heidbreder AF, Sands MS (2002) Inner ear pathology in the mucopolysaccharidosis VII mouse. Hear Res 169:69-84. CrossRef Medline

Ohlemiller KK, Rice ME, Gagnon PM (2008) Strial microvascular pathology and age-associated endocochlear potential decline in NOD congenic mice. Hear Res 244:85-97. CrossRef Medline

Oku Y, Murakami K, Irie K, Hoseki J, Sakai Y (2017) Synthesized a $\beta 42$ caused intracellular oxidative damage, leading to cell death, via lysosome rupture. Cell Struct Funct 42:71-79. CrossRef Medline

Ono K, Wang X, Han J (2001) Resistance to tumor necrosis factor-induced cell death mediated by PMCA4 deficiency. Mol Cell Biol 21:8276-8288. CrossRef Medline

Ono K, Kim SO, Han J (2003) Susceptibility of lysosomes to rupture is a determinant for plasma membrane disruption in tumor necrosis factor alpha-induced cell death. Mol Cell Biol 23:665-676. CrossRef Medline

Parham K (1997) Distortion product otoacoustic emissions in the C57BL/6J mouse model of age-related hearing loss. Hear Res 112:216-234. CrossRef Medline

Potter PK, Bowl MR, Jeyarajan P, Wisby L, Blease A, Goldsworthy ME, Simon MM, Greenaway S, Michel V, Barnard A, Aguilar C, Agnew T, Banks G, Blake A, Chessum L, Dorning J, Falcone S, Goosey L, Harris S, Haynes A, et al. (2016) Novel gene function revealed by mouse mutagenesis screens for models of age-related disease. Nat Commun 7:12444. CrossRef Medline

Raben N, Shea L, Hill V, Plotz P (2009) Chapter 21 Monitoring Autophagy in Lysosomal Storage Disorders. In: Autophagy in Disease and Clinical Applications, Part C, pp 417-449. CrossRef

Raposo G, Marks MS (2002) The dark side of lysosome-related organelles: specialization of the endocytic pathway for melanosome biogenesis. Traffic 3:237-248. CrossRef Medline

Remis NN, Wiwatpanit T, Castiglioni AJ, Flores EN, Cantú JA, GarcíaAñoveros J (2014) Mucolipin co-deficiency causes accelerated endolysosomal vacuolation of enterocytes and failure-to-thrive from birth to weaning. PLoS Genet 10:e1004833. CrossRef Medline

Repnik U, Hafner Česen M, Turk B (2014) Lysosomal membrane permeabilization in cell death: concepts and challenges. Mitochondrion 19:4957. CrossRef Medline

Schachern PA, Cureoglu S, Tsuprun V, Paparella MM, Whitley CB (2007) Age-related functional and histopathological changes of the ear in the MPS I mouse. Int J Pediatr Otorhinolaryngol 71:197-203. CrossRef Medline

Schiaffino MV (2010) Signaling pathways in melanosome biogenesis and pathology. Int J Biochem Cell Biol 42:1094-1104. CrossRef Medline
Schiffmann R, Grishchuk Y, Goldin E (1993) Mucolipidosis IV. In: GeneReviews (Pagon RA, Adam MP, Ardinger HH, Wallace SE, Amemiya A, Bean LJ, Bird TD, Fong CT, Mefford HC, Smith RJ, Stephens K, eds). Seattle, Washington: University of Washington.

Schröder BA, Wrocklage C, Hasilik A, Saftig P (2010) The proteome of lysosomes. Proteomics 10:4053-4076. CrossRef Medline

Seal RP, Akil O, Yi E, Weber CM, Grant L, Yoo J, Clause A, Kandler K, Noebels JL, Glowatzki E, Lustig LR, Edwards RH (2008) Sensorineural deafness and seizures in mice lacking vesicular glutamate transporter 3. Neuron 57:263-275. CrossRef Medline

Seo YJ, Ju HM, Lee SH, Kwak SH, Kang MJ, Yoon JH, Kim CH, Cho HJ (2017) Damage of inner ear sensory hair cells via mitochondrial loss in a murine model of sleep apnea with chronic intermittent hypoxia. Sleep 40:9. CrossRef Medline

Slaugenhaupt SA (2002) The molecular basis of mucolipidosis type IV. Curr Mol Med 2:445-450. CrossRef Medline

Spongr VP, Flood DG, Frisina RD, Salvi RJ (1997) Quantitative measures of hair cell loss in CBA and C57BL/6 mice throughout their life spans. J Acoust Soc Am 101:3546-3553. CrossRef Medline

Thompson EG, Schaheen L, Dang H, Fares H (2007) Lysosomal trafficking functions of mucolipin-1 in murine macrophages. BMC Cell Biol 8:54. CrossRef Medline

Trump BF, Berezesky IK, Chang SH, Phelps PC (1997) The pathways of cell death: oncosis, apoptosis, and necrosis. Toxicol Pathol 25:82-88. CrossRef Medline

Turk B, Turk D, Turk V (2012) Protease signalling: the cutting edge. EMBO J 31:1630-1643. CrossRef Medline

Vasiljeva O, Dolinar M, Pungercar JR, Turk V, Turk B (2005) Recombinant human procathepsin $\mathrm{S}$ is capable of autocatalytic processing at neutral $\mathrm{pH}$ in the presence of glycosaminoglycans. FEBS Lett 579:1285-1290. CrossRef Medline

Venugopal B, Browning MF, Curcio-Morelli C, Varro A, Michaud N, Nanthakumar N, Walkley SU, Pickel J, Slaugenhaupt SA (2007) Neurologic, gastric, and ophthalmologic pathologies in a murine model of mucolipidosis type IV. Am J Hum Genet 81:1070-1083. CrossRef Medline

Wangemann P (2006) Supporting sensory transduction: cochlear fluid homeostasis and the endocochlear potential. J Physiol 576:11-21. CrossRef Medline

Westermann B (2012) Bioenergetic role of mitochondrial fusion and fission. Biochim Biophys Acta 1817:1833-1838. CrossRef Medline

Willott JF (2006) Measurement of the auditory brainstem response (ABR) to study auditory sensitivity in mice. Curr Protoc Neurosci 8:8.21B. CrossRef Medline

Xu H, Delling M, Li L, Dong X, Clapham DE (2007) Activating mutation in a mucolipin transient receptor potential channel leads to melanocyte loss in Varitint-Waddler mice. Proc Natl Acad Sci U S A 104:18321-18326. CrossRef Medline

Yang H, Gan J, Xie X, Deng M, Feng L, Chen X, Gao Z, Gan L (2010) Gfil-cre knock-in mouse line: a tool for inner ear hair cell-specific gene deletion. Genesis 48:400-406. CrossRef Medline

Zeevi DA, Frumkin A, Bach G (2007) TRPML and lysosomal function. Biochim Biophys Acta 1772:851-858. CrossRef Medline 